OPEN ACCESS

Edited by:

Eckart Förster,

Ruhr University Bochum, Germany

Reviewed by:

Kenji Shimamura, Kumamoto University, Japan

Yves Combarnous,

Centre National de la Recherche

Scientifique (CNRS), France

*Correspondence:

Roberto Maggi

roberto.maggi@unimi.it

${ }^{\dagger}$ These authors share last authorship

Specialty section:

This article was submitted to

Cell Adhesion and Migration,

a section of the journal

Frontiers in Cell and Developmental

Biology

Received: 15 December 2021

Accepted: 17 January 2022

Published: 11 February 2022

Citation:

Di Schiavi E, Vistoli G, Moretti RM,

Corrado I, Zuccarini G, Gervasoni S,

Casati L, Bottai D, Merlo GR and

Maggi $R$ (2022) Anosmin-1-Like Effect

of UMODL1/Olfactorin on the

Chemomigration of Mouse GnRH

Neurons and Zebrafish Olfactory

Axons Development.

Front. Cell Dev. Biol. 10:836179.

doi: $10.3389 /$ fcell.2022.836179

\section{Anosmin-1-Like Effect of UMODL1/ Olfactorin on the Chemomigration of Mouse GnRH Neurons and Zebrafish Olfactory Axons Development}

Elia Di Schiavi ${ }^{1}$, Giulio Vistoli ${ }^{2}$, Roberta Manuela Moretti ${ }^{3}$, Ilaria Corrado ${ }^{4}$, Giulia Zuccarini ${ }^{4}$, Silvia Gervasoni ${ }^{2}$, Lavinia Casati ${ }^{2}$, Daniele Bottai ${ }^{2}$, Giorgio Roberto Merlo ${ }^{4 t}$ and Roberto Maggi ${ }^{2 * t}$

${ }^{1}$ Institute of Biosciences and Bioresources, National Research Council of Italy, Naples, Italy, ${ }^{2}$ Department of Pharmaceutical Sciences DISFARM, Università degli Studi di Milano, Milano, Italy, ${ }^{3}$ Department of Pharmacological and Biomolecular Sciences DISFEB, Università degli Studi di Milano, Milano, Italy, ${ }^{4}$ Department Molecular Biotechnology and Health Science, University of Torino, Torino, Italy

The impairment of development/migration of hypothalamic gonadotropin-releasing hormone $(\mathrm{GnRH})$ neurons is the main cause of Kallmann's syndrome (KS), an inherited disorder characterized by hypogonadism, anosmia, and other developmental defects. Olfactorin is an extracellular matrix protein encoded by the UMODL1 (uromodulin-like 1) gene expressed in the mouse olfactory region along the migratory route of $\mathrm{GnRH}$ neurons. It shares a combination of WAP and FNIII repeats, expressed in complementary domains, with anosmin-1, the product of the ANOS1 gene, identified as the causative of KS. In the present study, we have investigated the effects of olfactorin in vitro and in vivo models. The results show that olfactorin exerts an anosmin-1-like strong chemoattractant effect on mouse-immortalized GnRH neurons (GN11 cells) through the activation of the FGFR and MAPK pathways. In silico analysis of olfactorin and anosmin-1 reveals a satisfactory similarity at the N-terminal region for the overall arrangement of corresponding WAP and FNIII domains and marked similarities between WAP domains' binding modes of interaction with the resolved FGFR1-FGF2 complex. Finally, in vivo experiments show that the down-modulation of the zebrafish z-umodl1 gene (orthologous of UMODL1) in both GnRH3:GFP and omp ${ }^{2 k}$ :gap-CFP'w034 transgenic zebrafish strains leads to a clear disorganization and altered fasciculation of the neurites of GnRH3:GFP neurons crossing at the anterior commissure and a significant increase in olfactory CFP + fibers with altered trajectory. Thus, our study shows olfactorin as an additional factor involved in the development of olfactory and $\mathrm{GnRH}$ systems and proposes UMODL1 as a gene worthy of diagnostic investigation in KS.

Keywords: GnRH (gonadotropin-releasing hormone), anosmin-1, olfactorin, UMODL1, hypothalamus and neuroendocrinology, olfactory axons, anosmia, development 


\section{INTRODUCTION}

Reproduction in mammals is under the control of a complex interaction of neuronal and hormonal factors. The hypothalamic decapeptide gonadotropin-releasing hormone $(\mathrm{GnRH})$ plays the role of the master regulator of the hormonal reproductive axis (Maggi et al., 2016; Limonta et al., 2018; Maggi, 2020).

Kallmann's syndrome (KS) is a developmental genetic disease characterized by the association of hypogonadotropic hypogonadism and anosmia, defined as the complete or partial loss of olfaction/smell resulting from a developmental defect of the olfactory bulb (OB) (Maccoll et al., 2010). KS patients usually show low levels of circulating gonadotropins due to the impairment of the development and function of the GnRH neuronal system (Schwanzel-Fukuda et al., 1989; Cariboni and Maggi, 2006).

$\mathrm{KS}$ is the most common genetic cause of hypogonadotropic infertility with an estimated prevalence of 1/8-10.000 males and 1/40-50.000 females with a high percentage of sporadic forms (Dodé and Hardelin, 2009). KS is genetically highly heterogeneous, with more than 20 mutated genes identified and validated as the likely cause of the disease (Swee et al., 2021). ANOS1 was the first gene identified whose mutations, relatively frequent, cause the X-linked form of KS (Franco et al., 1991; De Castro et al., 2017). Immunocytochemical data consistently show that X-linked $\mathrm{KS}$ is due to an altered development of olfactory axons and migration of $\mathrm{GnRH}$ neurons (Schwanzel-Fukuda et al., 1989).

In addition to olfactory and gonadotropic defects, deletions or loss-of-function mutations of the ANOS1 gene are associated with the KS phenotype and other developmental defects (midline abnormality, cleft palate) found in different forms of $\mathrm{KS}$ (Maccoll et al., 2010; Stamou and Georgopoulos, 2018).

ANOS1 is expressed in different structures of the central nervous system, including the olfactory bulb and other components of the olfactory regions, retina, cerebellum, and spinal cord, during embryonic development and in adulthood (Hu et al., 2011).

The ANOS1 gene encodes for the protein anosmin-1, a 680 amino acid glycoprotein characterized by several domains, as a cysteine-rich region, a whey acidic protein domain (WAP), four consecutive fibronectin type III-like domains (FNIII), and a C-terminal region rich in basic histidine and prolines (SoussiYanicostas et al., 1996; Hardelin et al., 1999); moreover, there are five potential heparan sulfate-binding sites. The WAP domain, present in protease inhibitors, FNIII domains, and many extracellular matrix proteins, was found to be involved in axonogenesis and neuronal migration (Hu et al., 2004).

Anosmin-1 was found to affect cell adhesion and migration (Bribián et al., 2008), neurite outgrowth and branching (Rugarli et al., 2002; Soussi-Yanicostas et al., 2002; Cariboni et al., 2004; Di Schiavi and Andrenacci, 2013), neurogenesis (García-González et al., 2016), oligodendrocytes differentiation, and myelin formation (Murcia-Belmonte et al., 2016), through the interaction with heparan sulfate proteoglycans (HSPG) and fibroblast growth factors (FGFs)/fibroblast growth factor receptor (FGFR) complexes (Bülow et al., 2002; Hu et al., 2009).
In vitro studies showed that anosmin-1 may exert a chemotactic effect on a mouse's GnRH neuronal cell line (Cariboni et al., 2004). The migration of $\mathrm{GnRH}$ neurons from the olfactory placode to the hypothalamic region is a mandatory developmental mechanism to gain normal reproductive functions; it is extensively studied in several species and expected to be highly conserved (Tobet et al., 1997; Cho et al., 2019; Duan and Allard, 2020). Surprisingly, the ANOS1 gene shows an unusual pattern of conservation across species; it is largely conserved from invertebrates to primates, but no ANOS1 ortholog has been so far identified in mice and rats, making the functional characterization of anosmin-1, using classical rodent models, not possible (Maccoll et al., 2010).

A number of secreted and membrane molecules have been suggested to be implicated in the guidance and targeting of olfactory sensory neurons in rodents (Reed, 2004). Among them, we have described in the mouse a protein that we named olfactorin; olfactorin is the product of the mouse's uromodulin like-1 (Umodl1) gene and may represent a potential new element in this process (Di Schiavi et al., 2005). The Umodl1 gene is located on chromosome 17 in mice and chromosome 21 in humans (Shibuya et al., 2004); the encoded protein has the features of a secreted modular protein containing domains typically present in extracellular matrix proteins (EMI, WAP, FNIII, Ca2+-binding EGF-like, SEA, and ZP domains). During a mouse's embryonic development (from embryonic day 16.5), the expression of the Umodll gene is confined to a subset of olfactory neurons in the olfactory epithelium, where new sensory neurons projecting to olfactory bulbs and the vomeronasal organ are continually produced from a population of stem cells; such distribution is maintained or increased at birth and postnatally. This anatomical distribution is reminiscent of the immunodetection of anosmin-1 in zebrafish (Danio Rerio) (Yanicostas et al., 2009) and complementary of that of anosmin-1 in humans, mainly found in the olfactory bulb (Hardelin, 2001).

In addition to olfactory regions (Di Schiavi et al., 2005; Sammeta et al., 2010), the mouse's Umodl1 gene is expressed in the inner ear (Peters et al., 2007), in oocytes and thymic medulla (Wang et al., 2012) of the mouse. Human UMODL1 was found upregulated in cancer tissues originating from the lymph node, bladder, liver, pancreas, and ovary (Wang et al., 2012).

Little is known about the functions of the UMODL1 gene product. Mice overexpressing Umodl1 appear normal at a young age, but they develop premature infertility at the age of six months, possibly by a direct action on ovarian follicles (Wang et al., 2012); moreover, it has been reported that the UMODL1 gene product might play a critical role in susceptibility to high myopia (Nishizaki et al., 2009).

The peculiar distribution of Umodl1 gene expression and the structural domains of olfactorin lead to the assumption that they share functional similarities with anosmin-1. The present study was, therefore, designed to evaluate the role of olfactorin on the migration/development of GnRH neurons and olfactory axons using a multidisciplinary approach. We have examined in silico the different olfactorin domains, in vitro the migratory activity of mouse-immortalized GnRH neurons (GN11 cells) (Maggi et al., 
2000b; Cariboni et al., 2004; Maggi et al., 2005) exposed to mouse olfactorin, and in vivo the effect of the down-modulation of zUmodl1 in a developing zebrafish. The elucidation of olfactorin functions may contribute to the comprehension of the cellular and molecular mechanisms at the basis of olfactory development and explain the reproductive abnormalities of KS patients.

\section{MATERIALS AND METHODS}

\section{Cell Cultures}

COS-7 cells (American Type Culture Collection, ATCC, Manassas, VA, United States) were routinely grown in a monolayer at $37^{\circ} \mathrm{C}$ in a humidified $\mathrm{CO}_{2}$ incubator in the Dulbecco's minimum essential medium (DMEM) containing $1 \mathrm{mM}$ sodium pyruvate, $100 \mathrm{mg} / \mathrm{ml}$ streptomycin, $100 \mathrm{U} / \mathrm{ml}$ penicillin, and $10 \mathrm{mg} / \mathrm{L}$ of phenol red (Euroclone, Milano, Italy) and supplemented with $10 \%$ fetal bovine serum (FBS, Gibco, Grand Island, NY, United States). The medium was replaced at a 2-day interval. Subconfluent cells were routinely harvested by trypsinization and cultured in $57 \mathrm{~cm}^{2}$ dishes $(2.5 \times$ $10^{5}$ cells).

Mice's GN11 neurons were generously provided by S. Radovick (University of Chicago, Chicago, IL, United States) and routinely used in the author's lab (Maggi et al., 2000b; Cariboni et al., 2004; Maggi et al., 2005). The cells were routinely grown in a monolayer at $37^{\circ} \mathrm{C}$ in a humidified $\mathrm{CO}_{2}$ incubator in DMEM containing $1 \mathrm{mM}$ sodium pyruvate, $100 \mathrm{mg} /$ $\mathrm{ml}$ streptomycin, $100 \mathrm{U} / \mathrm{ml}$ penicillin, and $10 \mathrm{mg} / \mathrm{L}$ of phenol red (Euroclone, Milano, Italy) and supplemented with 10\% FBS (Gibco). The medium was replaced at a 2-day interval. Subconfluent cells were routinely harvested by trypsinization and seeded in $57 \mathrm{~cm}^{2}$ dishes (density $10^{5}$ cells/dish). Cells within six passages were used throughout the experiments.

\section{Production of Recombinant Olfactorin and Anosmin-1}

Recombinant mouse olfactorin and human anosmin-1 were obtained by the transfection of COS-7 cells (American Type Culture Collection, ATCC, Manassas, VA, United States) with the Umodl1 gene expression vector pCMV-Sport6.1-FLAG-BQ88765 and ANOS1 gene expression vector pMT21-KAL1myc, respectively, as described (Cariboni et al., 2004; Di Schiavi et al., 2005).

For transfection, cells (at $80 \%$ confluence) were grown in culture plates in a complete medium for $24 \mathrm{~h}$ and then transfected in the medium without FBS and antibiotics with lipofectamine reagent 2000 (Life Technologies, MD, United States), according to the manufacturer's instructions, with the selected expression vector $(1 \mu \mathrm{g} / \mathrm{ml})$ for 24 or $48 \mathrm{~h}$. The expression of the different constructs was verified by immunofluorescence and Western blot techniques.

The olfactorin- or anosmin-1-enriched medium (conditioned medium, CM) was obtained as follows: transfected COS-7 cells were left in the culture for $48 \mathrm{~h}$ in a complete medium; this was decanted and replaced with half the volume of a serum-free medium, and the cells were incubated for $16-18 \mathrm{~h}$ at $37^{\circ} \mathrm{C}$.

The CM was decanted in the presence of the protease inhibitor aprotinin $(0.5 \mathrm{mg} / \mathrm{ml})$, centrifuged at $3,000 \mathrm{~g}$ for $5 \mathrm{~min}$ at $4^{\circ} \mathrm{C}$, and immediately used for microchemotaxis assays.

\section{Production of Anti-Olfactorin Antiserum (OLF2-1)}

A recombinant fragment of mouse UMODL1 protein from Asp501 to Val850 was obtained by isopropyl-thiogalactoside (IPTG) induction of bacterial cultures harboring the corresponding construct in the pETM-11 vector. Antisera were obtained by the immunization of rabbits (Biopat, Piedimonte Matese, Caserta, Italy) with the residue obtained after solubilization in UREA 6M, Tris $50 \mathrm{mM}$ pH7.5, DTT $1 \mathrm{mM}$, $\mathrm{NaCl} 300 \mathrm{mM}$ and used as such in the subsequent Western blot analysis.

\section{Immunofluorescence}

Immunofluorescence of transfected cells was carried out as described (Cariboni et al., 2004).

For the immunodetection of the recombinant olfactorin monoclonal anti-FLAG M2 antibody (F1804-Sigma-Aldrich, St. Louis, MO, United States) and polyclonal anti-olfactorin antibodies, OLF2-1 were used.

Cells were grown on coverslips and fixed 2 days later in $4 \%$ buffered paraformaldehyde (20 min at $48 \mathrm{C}$ ), permeabilized with $0.2 \%$ Triton X-100 for $30 \mathrm{~min}$, blocked for $20 \mathrm{~min}$ with $1.5 \%$ horse normal serum in PBS, washed twice with PBS, and incubated at $4^{\circ} \mathrm{C}$ overnight with the specific antibody in $5 \%$ bovine serum albumin (BSA).

The cells were then washed in PBS and incubated for $1 \mathrm{~h}$ with FITC-conjugated secondary antibodies (1:200, Jackson Immunoresearch, West Grove, PA, United States). After a wash in deionized water, the coverslips were mounted with $\mathrm{DABCO}$ and viewed on a Zeiss Axioscope 2 Plus microscope under epifluorescence light.

\section{Western Blot Analysis}

After transfection (24 or $48 \mathrm{~h}$ ), cells were lysed in RIPA buffer $(0.05 \mathrm{~mol} / \mathrm{L}$ Tris $\mathrm{HCl} \mathrm{pH} \mathrm{7.7,} 0.15 \mathrm{~mol} / \mathrm{L} \mathrm{NaCl}, 0.8 \%$ SDS, $10 \mathrm{mmol} / \mathrm{L} \quad$ EDTA, $100 \mathrm{~mol} / \mathrm{L} \quad \mathrm{NaVO}_{4}, \quad 50 \mathrm{mmol} / \mathrm{L} \quad \mathrm{NaF}$, $0.3 \mathrm{mmol} / \mathrm{L} \mathrm{PMSF}$, and $5 \mathrm{mmol} / \mathrm{L}$ iodoacetic acid) containing leupeptin $(50 \mathrm{~g} / \mathrm{ml})$, aprotinin $(50 \mathrm{~L} / \mathrm{ml})$, and pepstatin $(50 \mathrm{~g} / \mathrm{ml})$ for $30 \mathrm{~min}$. The extracts were centrifuged at $12,000 \times g$ to remove insoluble materials, and the protein concentration was analyzed by using a BCA protein assay kit (Pierce, Thermo Fisher Scientific, Waltham, MA, United States). The conditioned medium (CM) obtained from transfected cells were centrifugated at $12,000 \times \mathrm{g}$ for $10 \mathrm{~min}$. The supernatants were concentrated and purified using $10 \mathrm{~K} \Omega$ Microsep Advance Centrifugal Devices (Pall Life Sciences, Port Washington, NY, United States).

Protein extracts $(30 \mu \mathrm{g})$ and concentrated MC $(20 \mu \mathrm{l})$ were separated through SDS gel electrophoresis and transferred to a PVDF membrane. After blocking, membranes were incubated 
overnight using the following antibodies: anti-FLAG M2 antibody (1:1,000) (F1804- Sigma Aldrich, United States) and anti-olfactorin (OLF2-1) (1:1,000). Peroxidase-conjugated secondary antibodies were used for $1 \mathrm{~h}$ at room temperature. The membranes were processed using the chemiluminescence kit Cyanagen Ultra (Cyanagen, Bologna, Italy). In each Western blot experiment, the tubulin expression (dilution 1:2,000) was evaluated as a loading control.

\section{Microchemotaxis Assay}

The chemomigration of mouse GN11 cells was analyzed using a 48-well Boyden's microchemotaxis chamber, according to the instructions (Neuroprobe, Cabin John, MD, United States) and carried out as previously described (Cariboni et al., 2004). For each chemomigration test, the response of the cells to $0.1 \%$ FBS was included as a general chemoattractant and internal control of cell responsiveness (Maggi et al., 2000a). Therefore, for graphical clarity, results are expressed as percent relative chemotactic response vs. $0.1 \%$ FBS stimulated cells.

The immunoneutralization of olfactorin was performed by incubating the $\mathrm{CM}$ in the presence of monoclonal anti-FLAG M2 antibodies (1:100 dilution, Sigma Aldrich, United States) for $30 \mathrm{~min}$ at $37^{\circ} \mathrm{C}$ before microchemotaxis experiments. HSPG competition was assayed by incubating the CM for $30 \mathrm{~min}$ at $37^{\circ} \mathrm{C}$ with $30 \mu \mathrm{g} / \mathrm{ml}$ heparin (sodium salt $\mathrm{H} 9399$, Sigma Aldrich).

For blocking experiments, GN11 cells were pre-incubated for $45 \mathrm{~min}$ at $37^{\circ} \mathrm{C}$ with inhibitors/blockers for MEK 1-2 (U0126, Invivogen, San Diego, CA, United States) (Favata et al., 1998), FGFR (BGJ398, Selleckchem) (Guagnano et al., 2011) VEGFR (AMG-706, Selleckchem) (Polverino et al., 2006), and HGFR pathways (SU11274, Selleckchem) (Sattler et al., 2003).

\section{Luciferase Assay}

The luciferase reporter p6xOSE2- Luc (which contains 6 tandem repeats of the osteoblast-specific core binding sequences of the FGF-responsive osteocalcin promoter (Kim et al., 2003; Park et al., 2010) was kindly provided by Mark J. McCabe, using the protocol described for the functional assessment of anosmin-1 (Mccabe et al., 2015).

GN11 cells were plated at 10000/well in a 24 well plate. One day before transfection, the media were replaced with a serumfree medium. Transfection with p6xOSE2- Luc was conducted with a Lipofectamine Reagent (Life Technologies, MD, United States), according to the manufacturer's instructions.

The efficiency of transfection was standardized to a constitutively active pSV- $\beta$-Galactosidase vector $(\beta-\mathrm{Gal})$ (Promega) internal control.

Cells used as positive controls were transfected with a PGL3 vector (PGL3CV) (Promega) constitutively expressing luciferase. The plasmids were used at the following concentrations: OSE $75 \mathrm{ng} / \mu \mathrm{l} ; \beta$-Gal $62.5 \mathrm{ng} / \mu \mathrm{l}$; and PGL3 CV $62.5 \mathrm{ng} / \mu \mathrm{l}$. Cells were incubated with a transfectant mixture for $3 \mathrm{~h}$ and $30 \mathrm{~min}$, decanted and cultured in DMEM with $8 \%$ FBS, and then incubated in a serum-free medium.

Two days after transfection, the cells were treated with recombinant FGF2 (PeproTech) in serum-free DMEM as the internal assay control; in addition, cells were exposed to the control CM or olfactorin-enriched CM with or without monoclonal anti-FLAG M2 antibodies (1:100 dilution; Sigma Aldrich, United States). The day after, cells were lysed, processed, and assayed for luciferase activity. Transcriptional activity was measured using a LucLite Kit (Perkin Elmer, Waltham, MA, United States) and the luciferase assay system (Promega), according to the manufacturer's protocols, as previously described (Crippa et al., 2010).

The $\beta$-Galactosidase activity was determined in the same samples with a colorimetric assay with the ortho-nitrophenyl$\beta$-galactoside (ONPG, $4 \mathrm{mg} / \mathrm{ml}$ ) substrate. The final values are expressed as relative luciferase activity normalized for the $\beta$-Gal signal.

\section{Zebrafish Strains and Treatments}

All procedures using zebrafishes are authorized by the Ethical Committee of the University of Torino and the Italian Ministry of Health (aut. N. 425/2016-PR, issued on 27 April 2016). Embryos and adult fish were raised and maintained under standard laboratory conditions. Fish were kept under a 14 h-light and $10 \mathrm{~h}$-dark photoperiod at approximately $28^{\circ} \mathrm{C}$. Allelic transmission followed the expected Mendelian ratios. Following fertilization, eggs were collected, and embryos (wild type or micro-injected) were grown in the presence of $0.003 \% 1$ phenyl-2-thiourea (PTU) to prevent the formation of the melanin pigment.

The fish strain gnrh3:EGFP, used to visualize the early GnRH3 neurons (Abraham et al., 2009, 2010; Garaffo et al., 2015; Zuccarini et al., 2019), was obtained from Dr. Y. Zohar (Univ. Maryland Biotechnology Institute, Baltimore, United States). The $o m p^{2 k}: g a p-C F P^{r w 034}$ strains were used to visualize the placodal olfactory neurons and their axons (Yoshida et al., 2002; Miyasaka et al., 2005; Sato et al., 2005); this strain was obtained from Drs. Nobuhiko Miyasaka and Yoshihiro Yoshihara (RIKEN Brain Science Institute, Japan). The omp:CFP transgene labels the OE-type neurons of the fish olfactory placode and all their extensions toward the olfactory bulbs (Sato et al., 2005).

To down-modulate $z$-umodl1, we utilized an antisense morpholino oligo (MO)-mediated strategy (GeneTools, Philomath, OR, United States) (Kloosterman and Plasterk, 2006; Flynt et al., 2007). Two MOs were designed: one that prevented intron1-exon2 splicing and consequently led to intron retention, and a second one annealing on the ATG start codon and preventing translation. $\mathrm{MO}$ sequences were designed with the online dedicated tool https://oligodesign.gene-tools.com/ request/. The sequence of the $\mathrm{MO}$ e2i2 splice junction blocker used is $5^{\prime \prime}$ TAGTTGAACATACTCACGCAAGGCA 3'; the sequence of the control mismatch $\mathrm{MO}$ used is $5^{\prime \prime}$ TAcTTcAAg ATACTgACcCAAGGCA 3'.

Fertilized eggs were collected at the single-cell stage and injected under stereological examination with $4 \mathrm{ng}$ of $\mathrm{MO}$ in the presence of phenol red for a further selection of the injected embryos. $48-72 \mathrm{~h}$ post-fertilization ( $\mathrm{hpf}$ ), embryos were fixed with $4 \%$ PFA at $4^{\circ} \mathrm{C} \mathrm{ON}$, washed in PBS, and embedded in $4 \%$ low melting agarose. The apical portion of the head was manually dissected from the rest of the embryo. 
gnrh3:EGFP + neurons were examined on fixed $72 \mathrm{hpf}$ embryos, at $\times 20$ and $\times 40$ magnification, by confocal microscopy. For counting, we followed the procedure detailed in Zhao et al. (2013). Briefly, stacks of Z-slices at $40 \times$ were used to manually count the GFP + neurons with the assistance of the ImageJ image-processing software (from NIH), after adjusting contrast and brightness. To avoid double-counting the same neuron, each optical slice ( $1 \mathrm{~mm}$-thick) was also individually re-examined. Merged images of all Z-slices confirmed the estimated number.

The omp:CFP + axons were viewed in a frontal plane. Confocal microscopy analysis was performed using a Leica TCS SP5 (Leica Microsystems). Images were acquired as Z-stacks of 1-mm thick optical sections.

\section{Homology Modelling}

The primary sequence of olfactorin was retrieved from UniProt for both the human and the muscarinic isoform (UniProt code Q5DID0 and Q5DID3, respectively). Given the high sequence identity, anosmin-1 was chosen as a template. The only resolved structure of anosimin-1 contains only the $\alpha$-carbon atoms of the backbone [PDB code: 1ZLG (Hu et al., 2005)]. Therefore, the remaining backbone atoms and the side chains were added using VEGA ZZ (Pedretti et al., 2021). Hydrogen atoms were added considering the physiological $\mathrm{pH}$, and finally, the structure was minimized using NAMD 2 (Phillips et al., 2005) and the CHARMM 22 force field, maintaining the backbone fixed to avoid denaturation.

For the model generation, only the first 700 amino acids of olfactorin were considered to favor the local alignment of the WAP and FnIII domains. The alignment was performed by using NIH Cobalt (Papadopoulos and Agarwala, 2007) and the Blosum62 alignment matrix. Then, this alignment was used by Modeller 9.16 (Sali and Blundell, 1993) to generate the homology model. The best model was chosen according to the DOPE and GA341 scores and the Ramachandran plot.

\section{Protein-Protein Docking}

To assess how olfactorin and anosmin-1 interact with FGFR1, we performed a rigid protein-protein docking. The FGFR1 structure in the complex with FGF2 was retrieved from the Protein Data Bank (PDB code: 1FQ9) (Schlessinger et al., 2000), while for olfactorin and anosmin-1 we used the homology models obtained as described in the previous section. The docking calculations were performed by using GRAMM which applies an exhaustive 6-dimensional search through the translation and rotation of the molecules (Katchalski-Katzir et al., 1992). For the calculation, a grid step of 3.0 was used with $10^{\circ}$ angle for rotation, and 1,000 poses were generated. The best poses were chosen according to manual inspection and interaction energies computed by the pair interaction module of NAMD 2, using the CHARMM 22 force field.

\section{Statistical Analysis}

When not specified, statistical analysis was performed by ANOVA and adequate post hoc test.

\section{RESULTS}

\section{Olfactorin Shows Structural Similarity to Anosmin-1}

Sequence alignments of human and murine olfactorins reveal that the two proteins show a highly conserved primary sequence (identity equal to $76.1 \%$ ).

Olfactorin contains WAP (whey acidic protein), FN3 (fibronectin type 3) and EGF_Ca (calcium-binding EGF-like) domains, a SEA (sea urchin sperm protein, enterokinase, agrin), a ZP (zona pellucida) domain, and a TRANS (transmembrane) domain (Shibuya et al., 2004) (Figure 1A).

Alignment (NIH Cobalt) with anosmin-1 showed a 13\% identity for human and $12.9 \%$ identity for mouse olfactorins. Notably, both olfactorins and anosmin- 1 share in their N-terminal part a WAP and at least one FNIII domain with a good degree of similarity (identity percentages equal to 33 and $81 \%$, similarity for the WAP domain).

The 3D structures of human and mouse olfactorins (UniProt code hUMODL1: Q5DID0, mUMODL1:Q5DID3) were generated by homology modeling techniques based on the suitably prepared resolved structure of anosmin-1 (PDB code: 1ZLG) (Hu et al., 2005). The modeling was focused on the $\mathrm{N}$-terminal region comprising the first 700 residues of human and olfactorin that were aligned with the anosmin-1 sequence by $\mathrm{NIH}$ Cobalt (Papadopoulos and Agarwala, 2007) and used by Modeller (Webb and Sali, 2016) to generate the corresponding olfactorin structures.

The superimposition between anosmin-1 and human or mouse olfactorin structures (Figure 1B) reveals a similarity for both the local folding and the overall arrangement of the corresponding domains. A first comparison of the structures of olfactorin with anosmin-1 reveals that in anosmin-1 the domain FnIII.1 presents a $\beta$-sheet structure, while in the two models of UMODL1, this structure is still present but less extended. Conversely, the WAP domain assumes a very similar conformation in anosmin-1 and both olfactorin models (Figure 1C). In particular, the WAP domains show very similar structures, stabilized by two conserved disulfide bridges with a linker connecting the WAP and FnIII.1 domain markedly more extended in olfactorin and also including an EGF-like domain.

The olfactorin FnIII.1 domain compares well with the corresponding anosmin-1 domain, showing a similar folding characterized by a central $\beta$-sheet motif.

Both olfactorin models show disulfide bridges corresponding to those present in the anosmin-1 crystal: for human olfactorin in Cys154-Cys139 and Cys146-Cys121, for mouse olfactorin in Cys155-Cys140 and Cys147-Cys122. The protein folding surrounding these disulfide bridges is also similarly preserved in anosmin-1 and olfactorin (Figure 1C).

These data support the hypothesis that olfactorin could exert anosmin-1-like functions.

\section{Olfactorin Exerts a Chemomigratory Response of GN11 Cells Similar to Anosmin-1}

To test the possible effects of olfactorin on GnRH neuronal cells, we used the mouse GN11 cell line, a model that has been previously used to study the effects of anosmin-1 (Cariboni 


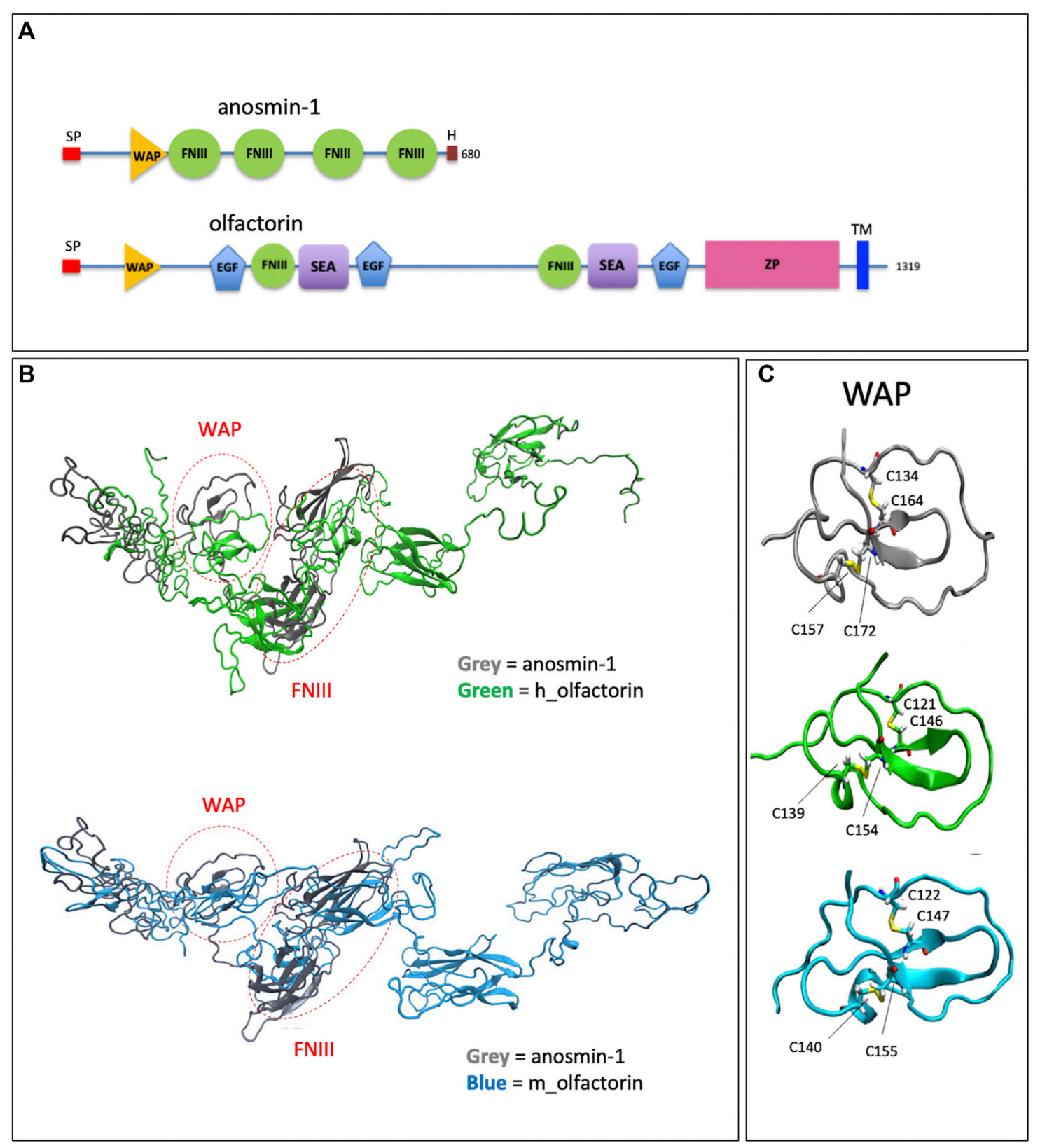

FIGURE 1 | Structural domains of olfactorin and anosmin-1 and analysis of their $\mathrm{N}$-terminal region. (A) The schematic comparison of the structures and of the main protein domains of anosmin-1 and olfactorin. (B) The ribbon representation of the domain solution structure model of human (green) and mouse (blue) olfactorins showing a similarity with human anosmin-1 (grey) in the N-terminal region of the molecules with common WAP (whey acidic protein-like) and FNIII (fibronectin type III) domains. (C) The ribbon representation and comparison of the WAP domains; the corresponding cysteine (C) residues forming disapplied bridges are evidenced. Abbreviations: EGF, calcium-binding EGF-like domain; FNIII, fibronectin type 3 domain; H, histidine-rich regions; SEA, sea urchin sperm protein; SP, signal; TM, transmembrane domain; WAP, whey acidic protein domain; ZP, zona pellucida domain.

et al., 2004) and of other attractants (Maggi et al., 2000b; Maggi et al., 2005) on the chemomigration of GnRH neurons. The conditioned medium (CM) of COS-7 transfected with Umodl1 expression vectors (pCMV-Sport6.1-FLAG-BQ88765, see Materials and Methods) were used as a source of recombinant olfactorin (olfactorin FLAG) (Di Schiavi et al., 2005). Recombinant olfactorin was efficiently expressed and secreted by COS-7 cells. Immunofluorescence of transfected cells shows a clear immunoreactivity for anti-FLAG monoclonal antibodies (Figure 2A). Western blot analysis of the whole-cell extract revealed that transfection leads to overexpression of a protein corresponding to the predicted size of the intracellular full-length Umodl1 gene product (about $148 \mathrm{kDa}$ ) (Figure 2B). In the $\mathrm{CM}$ of transfected COS-7 cells, we also found a shorter protein form, whose molecular weight was about $60-70 \mathrm{kDa}$ (Figure 2C). This form was detected using both the anti-olfactorin serum (OLF2-1) 


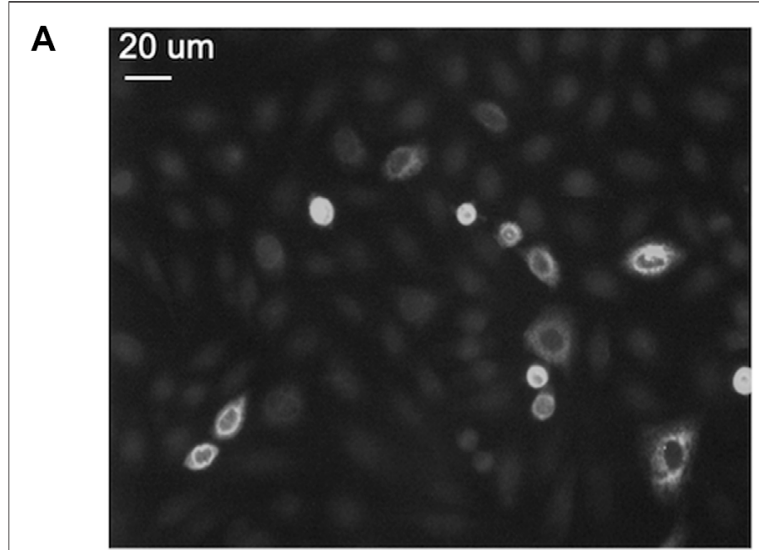

B C lipo olfactorin ${ }_{\text {FLAG }}$

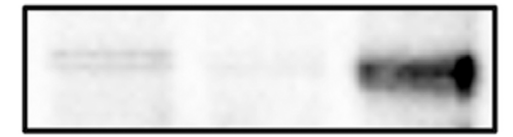

olfactorin-Ab

$-148 \mathrm{kDa}$

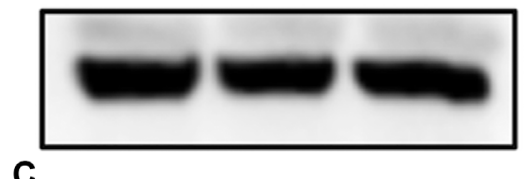

Tubulin-Ab

$-55 \mathrm{kDa}$

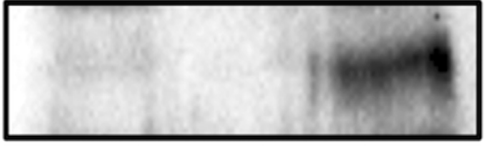

olfactorin-Ab

$-62 \mathrm{kDa}$

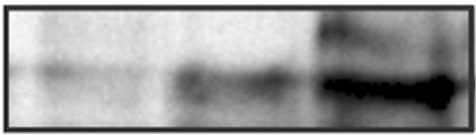

FLAG-Ab

$-62 \mathrm{kDa}$

FIGURE 2 | Identification of olfactorin in COS-7 cells transfected with the pCMV Sport6.1-FLAG-BQ887653 mouse Umodl1 expression vector. (A) Immunofluorescence detection of olfactorin with an anti-FLAG antibody in COS-7 cells transfected with the pCMV Sport6.1-FLAG-BQ887653

vector. (B) Olfactorin expression in COS-7 cells was evaluated by WB after

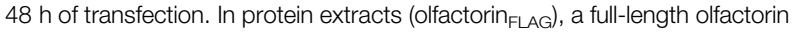
(148 kDa) detected with olfactorin-serum (olfactorin-Ab) was overexpressed; (C) in the CM of transfected cells the secreted form of olfactorin (62 kDa) was detected by both anti-olfactorin-serum and anti-FLAG-Ab. Experiments were performed independently three times, and a representative blot is shown. C: untrasfected cells; lipo: cells transfected with an empty vector.

and anti-FLAG antibody (recognizing the N-terminal FLAG sequence of the recombinant olfactorin). This result indicates that the N-terminal portion of olfactorin is released in the culture medium, and it might be compatible with the post-translational processing of olfactorin, that is, the cleavage of the full-length protein, that needs further experimental confirmation.

To test chemomigration, GN11 cells, placed in the Boyden's chamber, were exposed for $3 \mathrm{~h}$ to a gradient of CM obtained from COS-7 cells transfected with the empty vector (CM), Umodl1 (pCMV-Sport6.1-FLAG-BQ88765), or ANOS1 (pMT21-

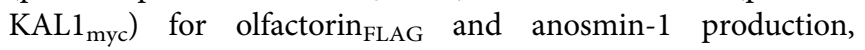
respectively, as described (Cariboni et al., 2004; Di Schiavi
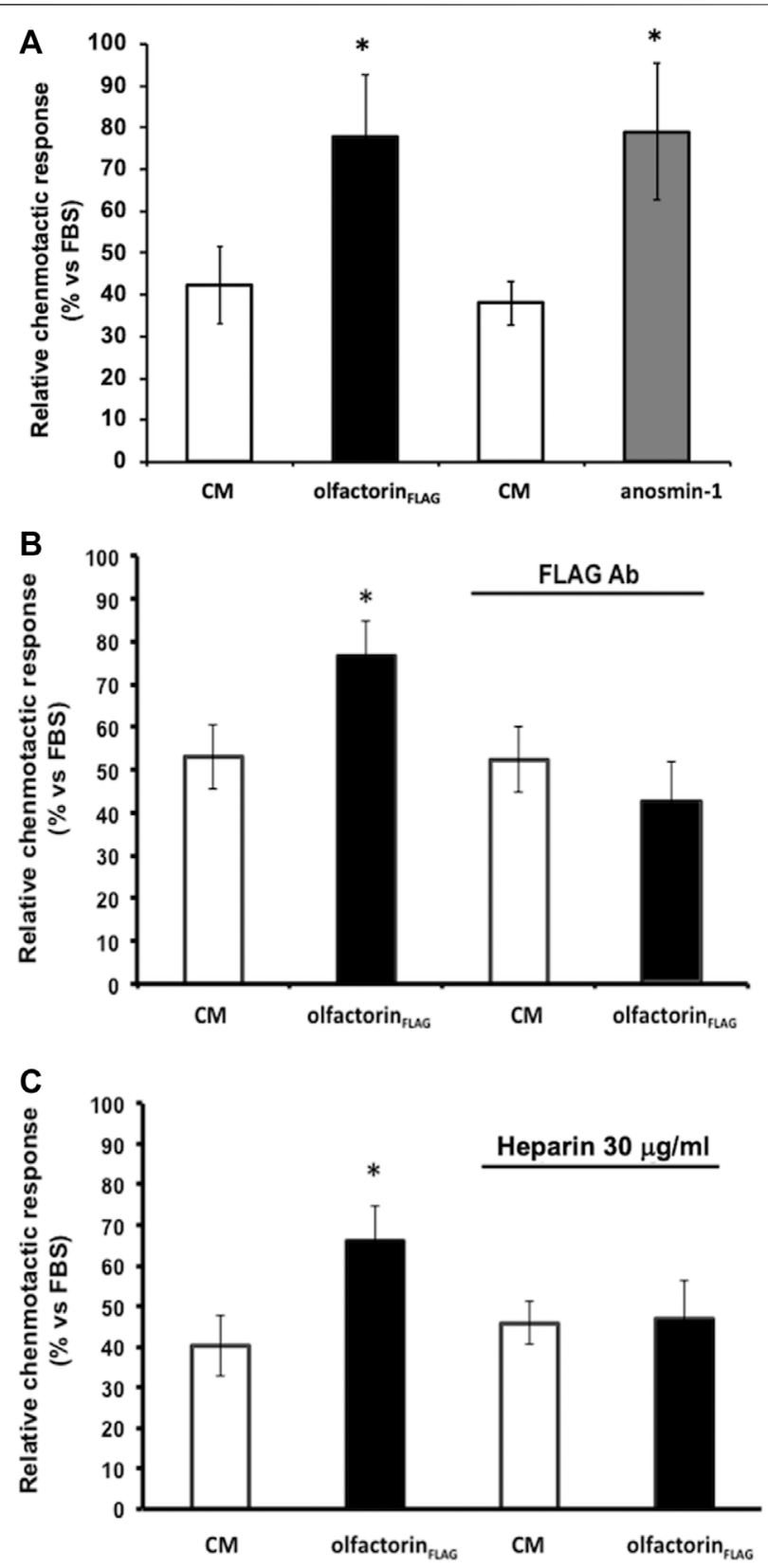

FIGURE 3 | Effects of the exposure to the olfactorin-enriched CM (olfactorin FLAG $_{\text {) }}$ on the chemomigration of GN11 cells. Microchemotaxis experiments were performed in the Boyden's chamber using the CM from COS-7 cells transfected with the empty vector (CM) or with PCMV SPORT6.1 PPT-FLAG-UMODL1 (the olfactorin-enriched CM; olfactorin FLAG) or pMT21myc-ANOS1 (the anosmin-1-enriched CM; anosmin-1). (A) Comparison of the chemotactic effects exerted by olfactorin- and anosmin-1enriched CMs on GN11 neurons. Internal controls for the procedure are represented by the chemotaxis to culture medium alone (DMEM) or culture medium with $0.1 \%$ Fetal Bovine Serum (FBS) as general chemoattractant. The results are expressed as the number of migrated cells per square $\mathrm{mm}$ of the porous membrane in $3 \mathrm{~h}$. Mean $\pm \mathrm{SD}$ from more than $4-6$ independent experiments. ${ }^{*} p<0.05$ vs respective CMs; ${ }^{* *} p<0.05$ vs DMEM. (B) Effect of immunoneutralization with a monoclonal anti-FLAG antibody on GN11 cell

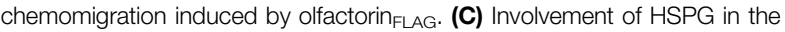
chemotaxis of GN11 cells induced by olfactorin ${ }_{\text {FLAG. The CM was }}$

(Continued) 
FIGURE 3 | preincubated at $37^{\circ} \mathrm{C}$ with $30 \mu \mathrm{g} / \mathrm{ml}$ heparin for $30 \mathrm{~min}$, prior the Boyden's chamber assay. The results (mean \pm SD; n. 6) are expressed as the relative chemotactic response of GN11 cells with respect to the stimulus exerted by $0.1 \%$ FBS. ${ }^{\star} p<0.05$ vs respective $\mathrm{CM}$.

et al., 2005), and the number of migrated cells per square mm of the porous membrane was measured. In each experiment, the response of the cells to $0.1 \%$ FBS was included as the internal control of the cell's responsiveness to chemotactic stimuli (Maggi et al., 2000a). For clarity purposes, the results are expressed as relative response vs GN11 cells exposed to $0.1 \%$ FBS (see Materials and Methods).

The CM obtained from untransfected COS-7 cells induced low but significant chemotaxis of GN11 cells, as previously observed (Cariboni et al., 2004) (Figure 3A). GN11 cells exposed to the olfactorin- or anosmin-1-enriched CM showed a significantly higher ( $+44 \%$ and $+45 \%$, respectively) chemotactic response than the control CM. To confirm the specificity of the olfactorin effect, we pre-incubated the control CM and olfactorin-the enriched $\mathrm{CM}$ with an anti-FLAG monoclonal antibody to block recombinant olfactorin. While the presence of the antibody did not affect the response elicited by the control CM, the immunoneutralization of recombinant olfactorin strongly reduced the chemomigration of GN11 cells induced by the olfactorin-enriched CM (Figure 3B).

Since heparin is known to compete with the binding of the anosmin-1 to heparan sulfate proteoglycans (HSPG), we tested the response of GN11 cells to the olfactorin-enriched CM in the presence and absence of heparin.

The addition of heparin did not affect the chemomigration of GN11 cells induced by the control CM; however, the increased chemomigration of GN11 cells elicited by the olfactorin-enriched $\mathrm{CM}$ was abolished via heparin treatment, suggesting its interaction with HSPG (Figure 3C).

\section{Olfactorin-Induced Chemomigration Is Mediated by the Activation of MAPK Pathways}

Although anosmin-1 was found to stimulate the chemomigration of GN11 cells, the mechanisms involved in such effect have not been so far elucidated.

We, therefore, investigated whether anosmin-1 and olfactorin could activate the same intracellular-signaling pathway. Prior to the microchemotaxis assay, GN11 cells were pretreated with the selective MEK1/2 inhibitor U0126 (1 $\mu \mathrm{M})$ (Favata et al., 1998) and then exposed to the anosmin-1- or olfactorin-enriched CMs. The pretreatment of cells with the inhibitor had no significant effects on cells exposed to the control CM but significantly decreased the chemo-attraction induced by anosmin- 1 to the levels of the control CM (Figure 4A), suggesting the activation of this pathway in anosmin-1-induced chemomigration of GN11 cells; this result was subsequently expanded and investigated and will be the topic of a subsequent communication (Maggi, in preparation). Similarly, the pretreatment of cells with the MAPK inhibitor decreased the chemo-attraction induced by the olfactorin-enriched CM (Figure 4B), indicating that olfactorin may exert its chemomigratory effect on GN11 neurons through the MEK1/2 pathway.

\section{Olfactorin-Induced Chemomigration is Inhibited by the FGFR Blocker}

Considering the known interaction of anosmin-1 with the FGF (fibroblast growth factor) type 1 receptor (FGFR1), we conducted chemomigration experiments using the commercially available inhibitors for FGFR1, VEGFR, and HGFR (cMet); these receptors are known to interact with HSPG, and their ligands are known to affect the migratory response of GnRH neurons (Giacobini et al., 2007; Chung et al., 2010; Cariboni et al., 2011). GN11 cells are responsive to VEGF and HGF (Maggi et al., 2005; Cariboni and Maggi, 2006), and the expression of FGFR1 was revealed by a previous transcriptomic analysis (data not shown). All the inhibitors were tested at the concentrations reported to block the receptors with the highest specificity, according to manufacturer's instructions and the scientific literature; moreover, a cytotoxicity assay preliminarily carried out (data

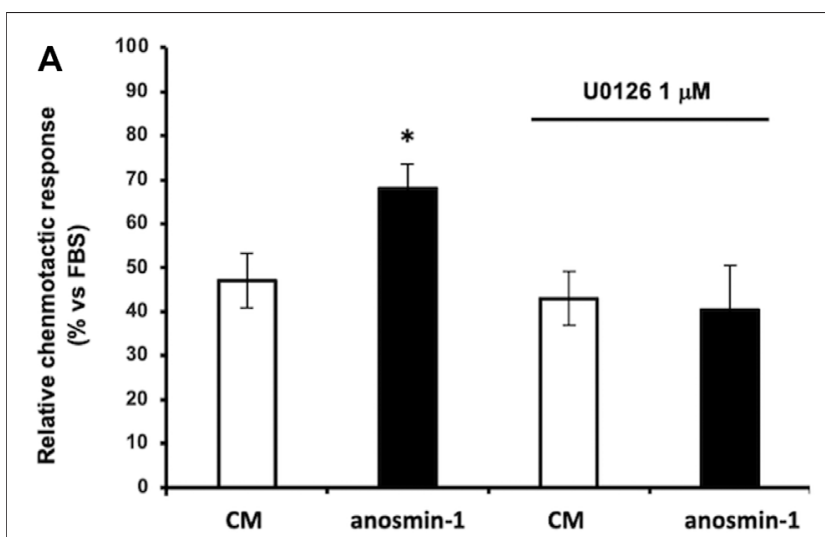

B

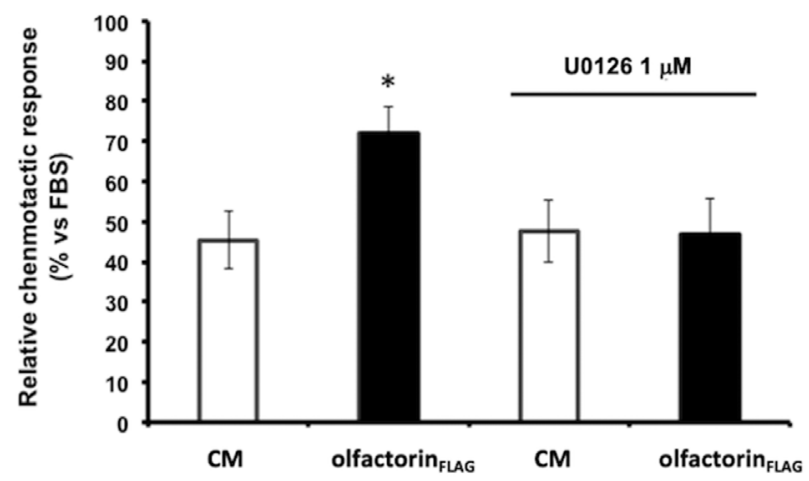

FIGURE 4 | Effect of the ERK1/2 signaling pathway inhibitor on

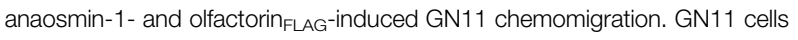
were pretreated with ERK1/2 inhibitor U0126 (1 $\mu \mathrm{M})$ and then to the exposed control CM, anosmin-1 (A) or olfactorin $F L A G$ (B). The results (mean \pm SD; n. 4) are expressed as the relative chemotactic response of GN11 cells with respect to the stimulus exerted by $0.1 \%$ FBS. ${ }^{*} p<0.05$ vs. respective $\mathrm{CM}$. 

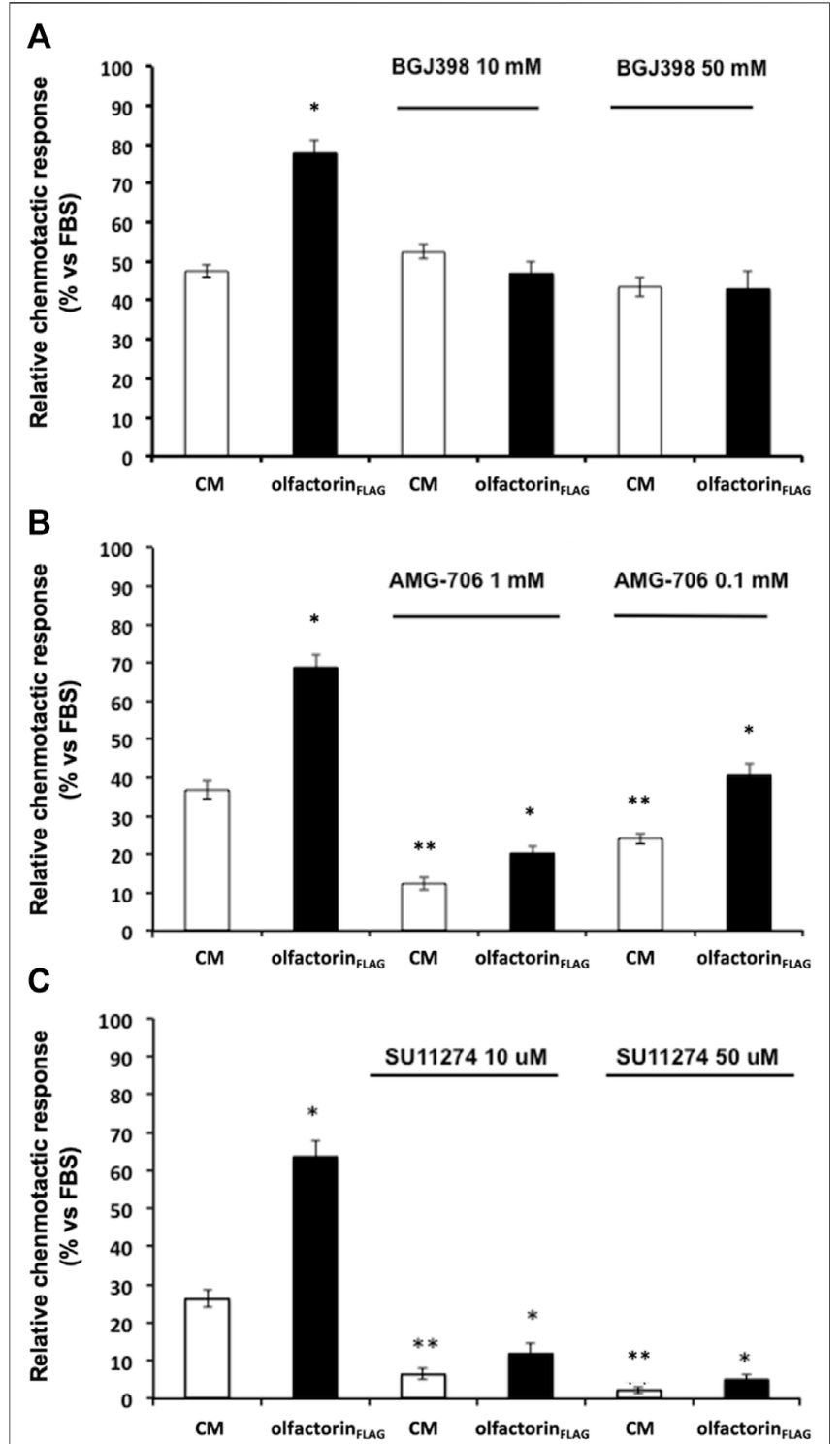

FIGURE 5 | Effect of growth factor receptor inhibitors on olfactorin FLAG $^{-}$ induced GN11 chemomigration. GN11 cells were pretreated with FGFR1-3 inhibitor BGJ398 (10 and $50 \mu \mathrm{M}$ ) (A), VEGFR inhibitor AMG-706 (1 and $0.1 \mu \mathrm{M})$ (B), HGFR inhibitor SU11274 (10 and $50 \mu \mathrm{M})$ (C) and exposed to the control CM or olfactorin $F$ FAG. The results (mean $\pm \mathrm{SD}$; $n$. 4) are expressed as the relative chemotactic response of GN11 cells with respect to the stimulus exerted by $0.1 \%$ FBS. ${ }^{\star} p<0.05$ vs. respective $\mathrm{CM}$; ${ }^{\star *} p<0.05$ vs. response to the $\mathrm{CM}$ of cells not pretreated with blockers.

not shown), for concentrations and time of exposure, excluded any toxic effects of the compounds.

The inhibitor BGJ398 interferes with the autophosphorylation of specific tyrosine residues present in wild-type FGFR1, FGFR2, and FGFR4 as well as FGFR3-K650E, FGFR3-S249C mutants (Guagnano et al., 2011). GN11 cells were pretreated with BGJ398, at 10 and $50 \mu \mathrm{M}$ concentrations, and then loaded into the Boyden's chamber and exposed to the control or olfactorin-enriched CMs. Unexpectedly, BGJ398 did not modify the chemotactic response of GN11 cells to the control CM and specifically counteracted the enhancement of the chemotactic response induced by the olfactorin-enriched CM at the two concentrations used, suggesting that FGF is not involved in this basal response (Figure 5A). This result suggests a possible positive interaction between the olfactorin- and FGF/FGFR1-signaling pathways and that the latter requires the presence of olfactorin to express its contribution on GN11 cell chemotaxis.

The effect of the VEGFR inhibitor AMG-706 (motesanib diphosphate) (Polverino et al., 2006) was then evaluated under the same experimental conditions described above. AMG-706 has a wide range of action toward the VEGFR family, including VEGFR1, VEGFR2, and VEGFR3, and it was used at a concentration of 0.1 and $1 \mu \mathrm{M}$. Treatment with AMG-706 resulted in a reduced chemoattraction of both the control and olfactorin-enriched CMs preparations (Figure 5B). However, a significant chemoattraction-enhancing effect of the olfactorinenriched CM of comparable magnitude to control (fold induction $1.80,1.66$, and 1.68 for $0,0.1$, and $1 \mu \mathrm{M}$ AMG-706, respectively) was still present in the presence of AMG-706. This result confirms a key role of VEGF produced by COS-7 cells in the chemoattraction induced by the control $\mathrm{CM}$ and tends to exclude a direct involvement of olfactorin in such effects.

Finally, we tested the possible interaction between the chemotropic effect of olfactorin and the hepatocyte growth factor (HGF) signaling using the HGFR inhibitor SU11247 (Sattler et al., 2003).

SU11274 selectively blocks the activity of Met-tyrosine kinases. GN11 cells were treated with SU11274 at 10 and $50 \mu \mathrm{M}$ and tested as above. We observed a significant strong reduction of the chemotactic response to both the control CM and olfactorin-enriched $\mathrm{CM}$ in the presence of SU11274 (Figure 5C). This indicates that HGF present in the CM is responsible for the chemomigration of GN11 cells induced by the control CM. On the other hand, the inhibitory action of SU11274 did not prevent the stimulatory effect of olfactorin that results in the same order of magnitude observed in the control $\mathrm{CM}$ (fold induction $2.41,1.83$, and 2.33 for 0,10 , and $50 \mu \mathrm{M}$ SU11247, respectively), thus excluding a direct role of HGF in the olfactorin effect.

These results show that the presence of VEGF and HGF blockers do not affect the chemotactic response to olfactorin on immortalized GnRH neurons and are suggestive of a main and direct involvement of FGFR in such effects.

\section{Olfactorin Induces a Transcriptional Effect Mediated by the FGFR-Mediated Pathway}

To confirm the involvement of FGFR in the olfactorin effect, we conducted a transcriptional assay to investigate the interaction of olfactorin with FGFR signaling. GN11 cells were transfected with the FGF-sensitive OSE luciferase reporter, and exposed to the CM and olfactorin-enriched CM. We applied the single-point protocol described (Mccabe et al., 2015) and FGF2 at 10 and $40 \mathrm{ng}$ was included as the control of the assay. The results (Figure 6A) show that FGF2, at the two concentrations tested, induced a significant luciferase activity in treated cells as compared to untreated cells. 


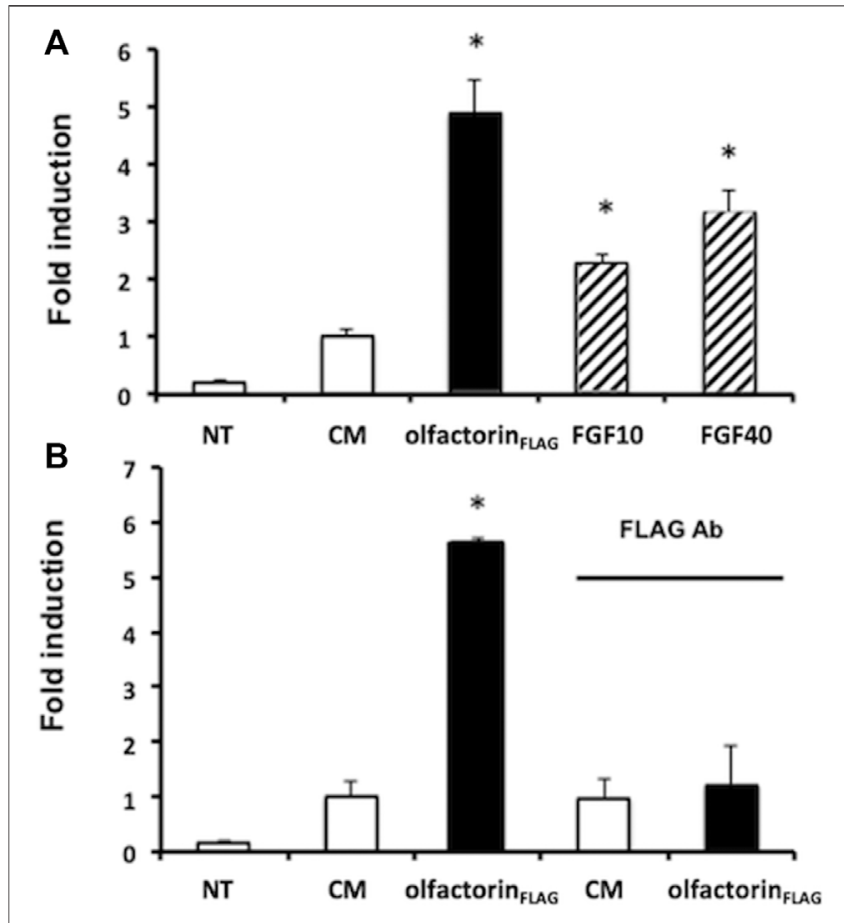

FIGURE 6 | Transcriptional analysis of olfactorin effects on GN11 cells. (A) GN11 neurons were transfected with OSE luciferase reporter and then exposed $24 \mathrm{~h}$ to increasing doses of FGF2 (at 10 and $40 \mathrm{ng}$ ), used as internal assay control, to the control $\mathrm{CM}$ and to olfactorin $\mathrm{FLAG}_{\text {. }}$ (B) Immunoneutralization of the olfactorin ${ }_{F L A G}$ by preincubation with the antiFLAG antibody. All treatments were done in triplicate, with cultures repeated three times in total; NT and control untreated cells. Data are presented as fold induction vs. CM (mean $\pm \mathrm{SD}$, n. 4). ${ }^{*} p<0.05$ vs NT; ${ }^{\star *} p<0.05$ vs $\mathrm{CM}$.

The control CM showed a basal luciferase activity possibly due to interfering factors, but the exposure of GN11 cells to the olfactorin-enriched CM induced a 3.5 fold higher luciferase reading, significantly greater than that of the control $\mathrm{CM}$. The treatment of the cells to anti-FLAG antibodies abolished the stimulatory response induced by olfactorin (Figure 6B).

\section{Similar Structural Interaction of Olfactorin and Anosmin-1 With the FGF-FGFR1 Complex}

Based on the domain similarity between anosmin-1 and olfactorin (Figure 1), further studies were performed to address the putative interactions that anosmin-1 and olfactorin can elicit with the complex FGF-FGFR1.

We focused on the potential interactions between the modeled structures of olfactorin structures with the resolved FGFR1-FGF2 complex (PDB code: 1FQ9) and its comparison with anosmin-1. The docking simulations were indeed based on the known and experimentally verified interaction between the $\mathrm{N}$-terminal region of anosmin-1 and the FGFR1-FGF2 complex that contributes to FGF signaling ( $\mathrm{Hu}$ et al., 2009). The experimental findings can be summarized as follows: 1) anosmin-1 binds more strongly to FGFR1 than to FGF2; 2) anosmin-1 binding to FGFR1 does not prevent the interaction with FGF2; and 3) mutational analyses indicate that the D2 region of FGFR1 should be most likely involved in anosmin-1 recognition. Docking simulations were focused on the D2 region, avoiding interferences with the known FGF2 binding region (i.e., around Arg250) but involving the sites for heparin binding (i.e., around Lys163 and Lys177). The same docking procedure based on the GRAMM software (Tovchigrechko and Vakser, 2006) was then applied to the segment WAP-FnIII.1 of both anosmin-1 and olfactorin. The results reveal marked similarities between the binding modes of the two simulated ternary complexes (Figure 7). About anosmin-1, the WAP domain properly contacts both D2 regions of the FGFR1 and FGF2 structures, while the FNIII.1 domain interacts with the apical part of the D2 region. Thus, olfactorin organizes its WAP domain in a very similar pose, while greater differences are seen in the FNIII.1 domain, whose interactions involve a larger portion of the D2 region than the corresponding contacts established by anosmin-1.

A closer analysis of the key interactions established by the similarly bound WAP domain reveals an extended network of ionic contacts which involves the acid residues of the WAP domain of both anosmin- 1 and olfactorin approaching the basic residues of both FGFR1 and, to a minor extent, FGF2. Figure 7 reports the crucial salt bridges stabilized by the anosmin-1 WAP domain with the FGFR1-FGF2 complex and the pivotal involvement of the sequence between Glu149 and Glu156 which elicits ionic interactions with positively charged residues of both FGFR1 and FGF2. While involving different residues of the WAP domain (e.g., Glu124 and Glu127), the ternary complex with olfactorin reveals a comparable network of ionic interactions engaging both FGFR1 and FGF2. Collectively, docking results suggest that anosmin- 1 and olfactorin can interact with the FGFR1-FGF2 complex through a reasonably similar binding mode in which the WAP domain plays a central role.

\section{The Functions of umodl1 In Vivo: the Effect on GnRH Neurons in Zebrafish}

In vivo experiments were conducted on zebrafish (Danio rerio) embryos that express the Umodl1 homolog $z$-umodl-1. To downmodulate the endogenous zebrafish umodl1 mRNA, we utilized an antisense morpholino oligo (MO)-mediated strategy (GeneTools, Philomath, OR, United States) (Kloosterman et al., 2006; Flynt et al., 2007). Using the tool at https:// oligodesign.gene-tools.com/request/, we designed one morpholino (MO) sequence, named SS, that anneals with the i1-e2-splicing site of both alternative transcripts of the $z$-umodl-1 mRNA and is predicted to block splicing at this site. A mismatch $\mathrm{MO}$ was also designed as the control. By interfering with the i1-e2 splicing, the SS MO is expected to cause aberrant splicing and consequent frame-shift mutation (Figure 8A). We tested the efficiency of the SS MO to deplete the mRNA by RT-PCR analysis of RNA samples derived from the whole WT embryos ( $48 \mathrm{hpf}$ ) injected with the SS MO at the single-cell stage and compared them to that of the embryos injected with the control MO. Treatment with the SS MO resulted in a clear decrease in the amount of $z$-umodl1 mRNA and the appearance of a smaller fragment lacking exon 2 of an expected size (Figure 8B). 


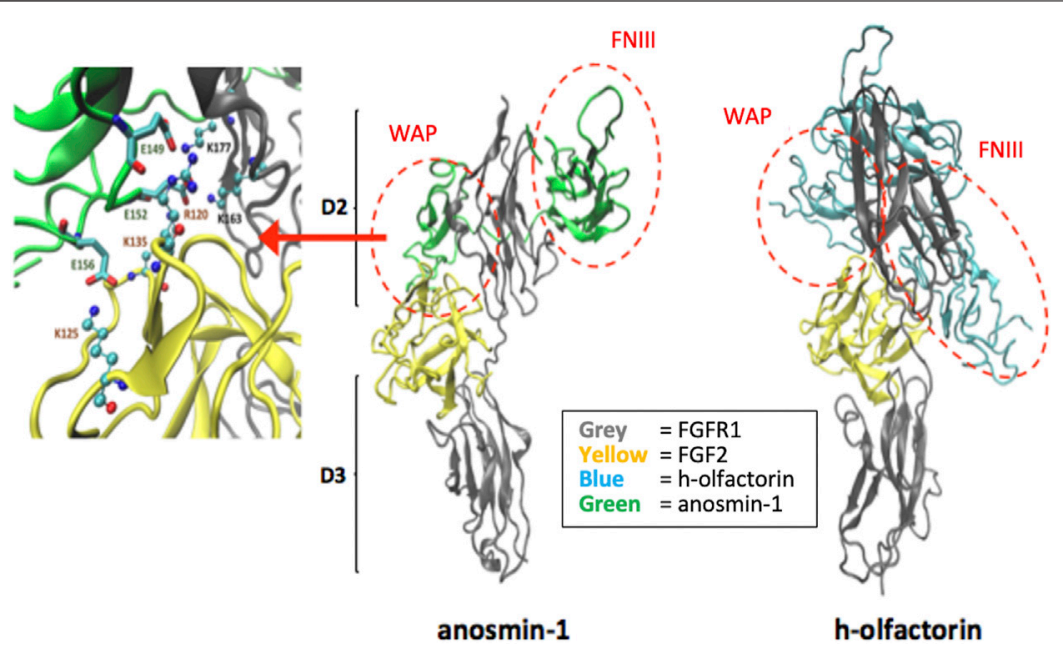

FIGURE 7|Potential interaction between the modeled human olfactorin structures with the resolved FGFR1-FGF2 complex (PDB code: 1FQ9) and its comparison with anosmin-1. As evidenced (red circles) WAP domains of olfactorin and anosmin-1 interact with the D2 domain of FGFR1 by assuming comparable arrangements. Greater differences are seen in the pose of the FNIII.1 domain; however, in both complexes it appears to conveniently approach the D2 domain of FGFR1. As shown in the left panel, the WAP-FGFR1 interactions appear to be mostly stabilized by ionic contacts.

The MOs were applied to the gnrh3:EGFP transgenic zebrafish strain, which expresses the EGFP reporter under the transcriptional control of the $\mathrm{z}$-gnrh3 promoter. The gnrh3: $E G F P+$ neurons consist of a population of terminal-nerveassociated cells that originates near olfactory placodes (OPs) and extend their neurites to project dorsally and ventrally into the forebrain, reaching the anterior commissure (AC), the postoptic commissure (POC), and the hypothalamus (Figure 8C) (Bassi et al., 2016; Zuccarini et al., 2019). The terminal-nerve-associated GnRH3+ neurons in the fish physiologically correspond to the olfactory-derived mammalian gonadotropic hypothalamic neurons (Abraham et al., 2008; Abraham et al., 2009; Wang et al., 2010). The expression of the gnrh3:EGFP transgene begins around 24-30 hpf, and no other marker is known to specifically identify the GnRH neurons at earlier stages.

We injected either the SS or control MOs in single-cell stage gnrh3:EGFP embryos, we examined them and the non-injected embryos at $72 \mathrm{hpf}$, and we determined the number, position, and neurite extension of the GFP + neurons, as previously done (Garaffo et al., 2015). For proper visualization of the neuronal arborization, we adopted the view plane shown in Figure 8D.

We observed no difference in the number of GFP + neurons (around $13^{+/-} 2$ per animal) and their position near the olfactory placode, comparing non-injected $(\mathrm{N}=30)$, mismatch MOinjected $(\mathrm{N}=16)$, and $\mathrm{z}$-umodl-1 SS-injected $(\mathrm{N}=12)$ embryos (Figures 8E-G).

We then examined the extension, orientation, and fasciculation of EGFP + fibers in the nasal region and basal forebrain. Upon the injection of the anti- $z$-umodll SS MOs, we noted that several EGFP + axons displayed an altered trajectory and/or aberrant fasciculation within the anterior commissure (Figures 8E-G). For quantification purposes, we defined "phenotype" as the condition in which we observe a) altered orientation and position of EGFP + fibers, b) altered fasciculation of EGFP + fibers at the commissures, or c) both of these together. The results were then expressed as the percentage of embryos showing the phenotype in various experimental conditions over the total number of embryos examined. We observe a significant increase in the fraction of embryos with the phenotype relative to the non-injected or mismatch injected ones (Figure 8I).

To rule out the indirect effects of the MOs, we examined morphological parameters of the entire embryos, including length, proportions, and shape. We did not observe morphological changes or developmental delays with any of the injected MOs as compared to non-injected or mismatchinjected embryos, as shown by low-magnification bright field images (Figure $\mathbf{8 H}$ ).

\section{The Functions of Umodl1 In Vivo: the Effect on Olfactory Neurons in Zebrafish}

We then extended the observation to the olfactory pathway since the origin and early development of GnRH3 neurons are closely linked to the development of the olfactory placode, and since in the mammalian embryos, the $\mathrm{GnRH}$ neurons migrate along the vomeronasal and olfactory nerves to the olfactory bulbs. We used the $o m p^{2 k}$ :gap-CFP ${ }^{r w 034}$ strain in which CFP (cyan fluorescent protein) marks the OMP + main olfactory neurons in the OP and their extensions toward the OB (Ishizaka et al., 2002; Miyasaka et al., 2005; Sato et al., 2005). This line provides efficient imaging of the early olfactory system (Garaffo et al., 2015). The relative position of the GnRH3+, the OMP + neurons, and their main extension is reported schematically in Figure 8C, while the view plane is shown in Figure 8D.

We injected the SS MO to deplete $z$-umodl1 into the OMP:CFP embryos at the single-cell stage and examined them at $72 \mathrm{hpf}$ by confocal microscopy. We defined "phenotype" as a) the presence of 
A

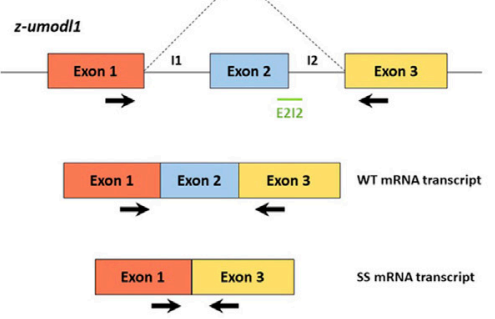

B

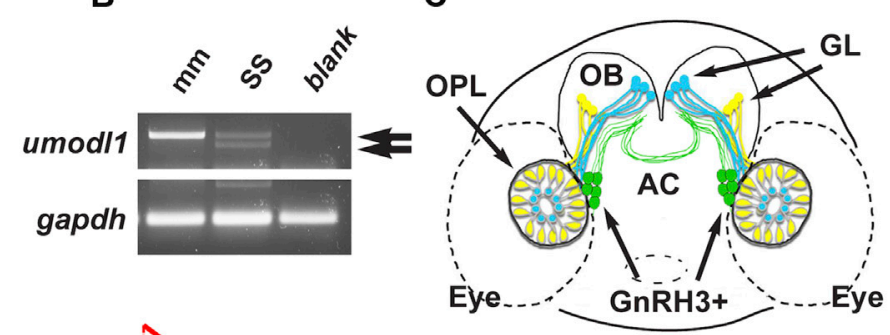

C

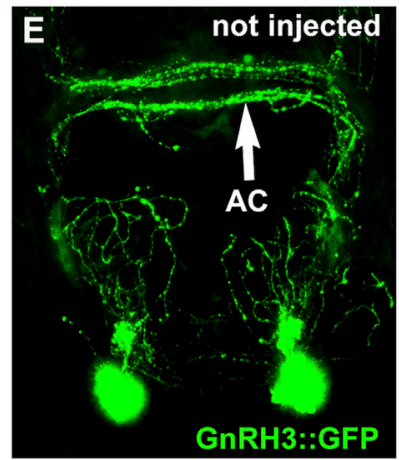

H

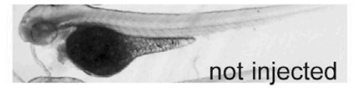

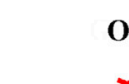
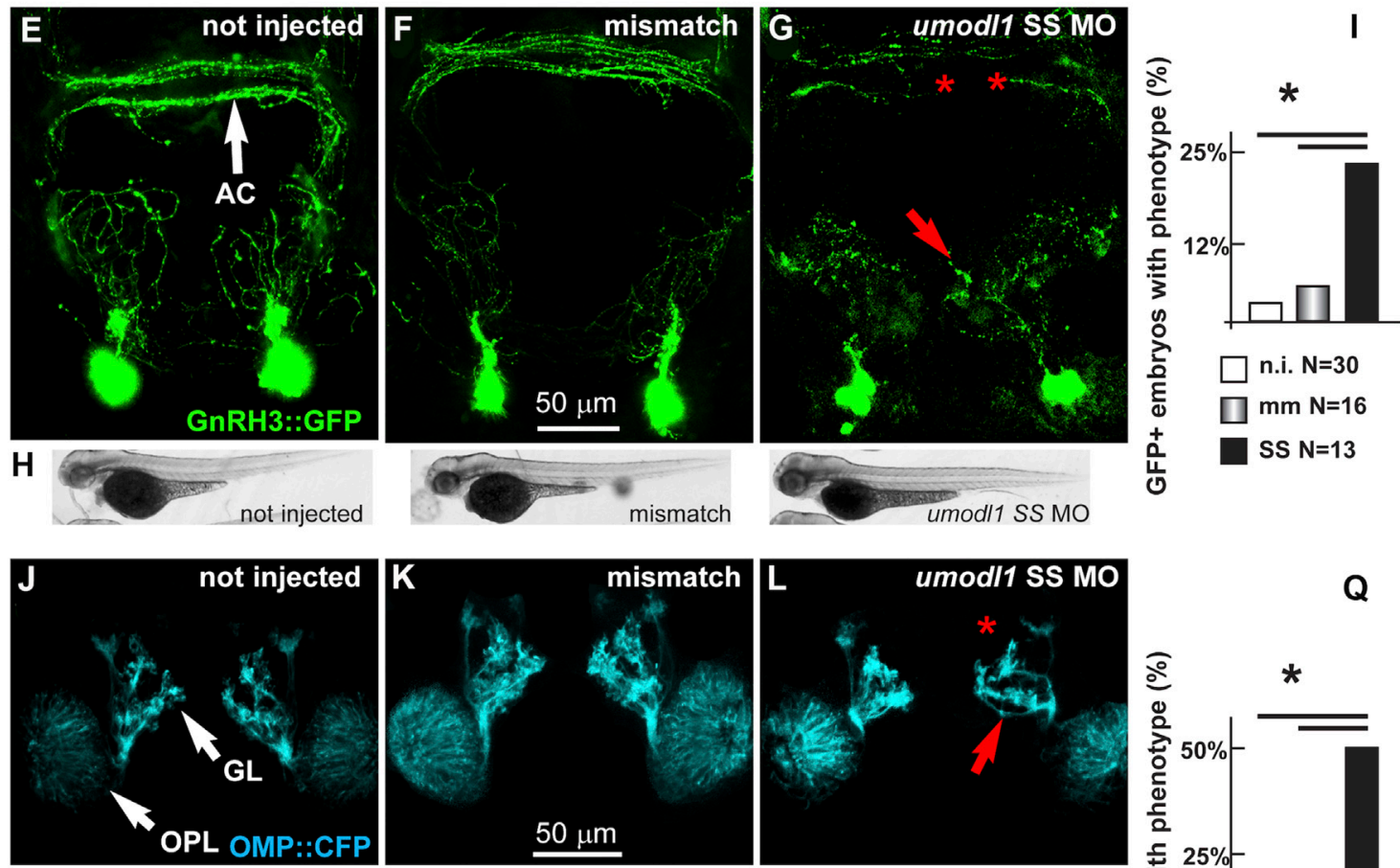

umodl1 SS MO

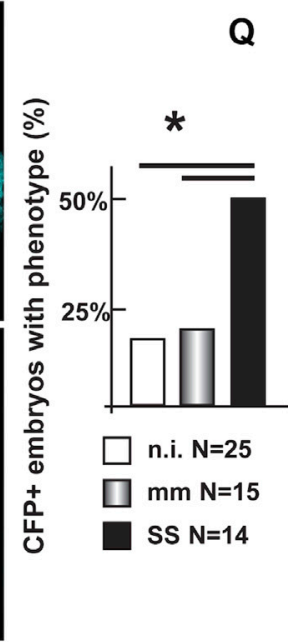

$\mathbf{P}$
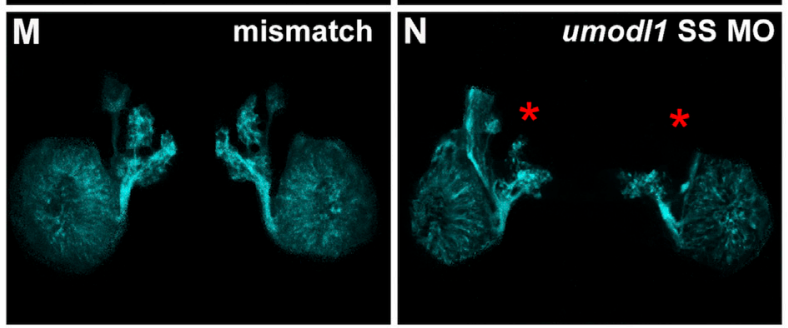

FIGURE 8|Depletion of z-umodl1 affects fasciculation, trajectory, and connectivity of GnRH3+ and OMP + neurons of the zebrafish olfactory system. (A). Scheme of exon/intron junctions of the z-umodl1 gene. The normal splicing is shown on the top, the abnormal splicing due to the Splice-Site (SS) MO is on the bottom. This altered splicing leads to a frame-shift mutation. Black arrows indicate the primers used for the mRNA analysis to detect the aberrant splicing.(B). RT-PCR analysis of RNA from mismatch and SS MO-injected embryos, amplified with the primers indicated in panel a. In the sample from SS MO-treated embryos an additional band lacking exon 2 is evident that is not present in the control sample. The $z$-gapdh mRNA was also detected for reference. (C). Scheme showing the positions of the GnRH3:GFP + neurons (in green), the OMP: CFP + neurons (in blue) and the Trcp2: Venus + neurons (in yellow, not used in this study) relative to the eyes, the olfactory placodes (OPL), the olfactory bulbs $(\mathrm{OB})$ and the olfactory nerves, in a frontal view. The anterior commissure (AC) is shown at the basis of the OB. (D). Scheme illustrating the view planes for the images of the $\mathrm{GnRH}+$ neurons (anterior-ventral) and for the OMP + neurons (frontal). GL, Glomeruli. (E-G). Micrographs of gnrh3:GFP zebrafish embryos that were either not injected (D) or injected with the control mismatched MO (E) or with anti-z-umodl1 SS (F) MO. In control injected embryos, no significant alteration was observed compared to not injected. White arrows indicate the normal position of the GFP + neurons. Red arrows and asterisks indicate, respectively, misrouted GFP + fibers and altered fasciculation or absent fibers. (H). Whole-mount bright field micrographs of embryos corresponding to the micrographs above, showing normal embryonic morphology and growth.(I). Quantification of the observed phenotype (altered fasciculation/trajectory), expressed as a percent of the injected GFP + embryos 
FIGURE 8 | showing the indicated phenotype, over the total number of GFP + embryos examined. Open boxes, not injected; grey-shaded boxes, mismatch MO; solid black boxes, anti-z-umodl1 SS MO. * indicates $p<0.05(\mathbf{J}-\mathbf{L})$. Micrographs of omp:CFP zebrafish embryos either not-injected (i), injected with the control mismatch MO (j) or injected with anti-z-umodl1 SS (K) MO at $400 \mu \mathrm{M}$ concentration. In control injected embryos, no significant alteration was observed compared to not injected. White arrows indicate the normal position of the olfactory placode (OPL) and of the glomeruli (GL). Red arrows and asterisks indicate, respectively, misrouted or misfasciculated OMP + fibers and absent glomeruli. (M, N). Same as in i-k, but the anti-z-umodl1 control and SS ( $\mathrm{m}$ and $\mathrm{n}) \mathrm{MO}$ were used at $800 \mu \mathrm{M}$ concentration. (P). Whole-mount bright field micrographs of embryos corresponding to the micrographs in j-n, showing normal embryonic morphology and growth. (Q). Quantification of the observed phenotypes (altered trajectory/glomerulogenesis), expressed as a percent of the injected CFP + embryos showing the indicated phenotype, over the total number of CFP + embryos examined. Open boxes, not injected; grey-shaded boxes, mismatch MO; solid black boxes, anti-z-umodl1 SS MO. ${ }^{\star} p$ < 0.05.

CFP + fibers with altered trajectory, b) the absence of one or more $\mathrm{CFP}+$ glomeruli, or c) both of these (Figures 8J-N). Upon injection with the SS MO $(\mathrm{N}=14)$, we observed a significant increase in the fraction of embryos showing the phenotype as compared to noninjected $(\mathrm{N}=25)$ or mismatch-injected $(\mathrm{N}=15)$ ones (Figure $8 Q$ ). We also quantified the intensity of CFP fluorescence as an estimation of the degree of differentiation reached by these neurons, as previously done (Garaffo et al., 2015). Still, we observed no difference, suggesting that umodl1 does not play a significant role in the differentiation of these receptor neurons. Finally, we examined basic morphological parameters of the treated fish embryos, as done before; the injection of the SS MO did not affect the growth and shape of the embryo as compared to those of the control embryos (Figure 8P).

\section{DISCUSSION}

We aimed to define the functional and structural similarity between olfactorin and anosmin-1, based on the previous observation of the distribution of Umodl1 expression along the migration pathway of olfactory axons and GnRH neurons (Di Schiavi et al., 2005), and structural similarity between the two factors. We now document a strong molecular similarity of the N-terminal fragment of olfactorin with anosmin-1, for the WAP and FNIII domains, known to mediate the interaction of anosmin-1 with the HSPG and FGF/FGFR complexes (Bülow et al., 2002; Hu et al., 2009). We demonstrate a chemotropic action of olfactorin on GN11 cells similar to the one exerted by anosmin-1 (Cariboni et al., 2004), and we show the involvement of HSPG and FGFR in this response. Moreover, we show that the depletion of Umodl1 in zebrafish leads to an abnormal position, direction, and fasciculation of $\mathrm{GnRH} 3$ neuron fibers as well as of the olfactory fibers.

A series of experiments were carried out to characterize the effect of olfactorin on the GN11 chemotactic response and to check whether this could be similar to the one already observed for anosmin-1.

First, the transfection of the olfactorin-expression vector in COS-7 cells shows that the protein is efficiently expressed and secreted; moreover, while a complete protein is present in the whole cell extract, an N-terminal fragment including the WAP and FNIII domains was detected in cell-conditioned media, suggesting a possible new still undetermined processing in the biosynthesis of olfactorin.

The results obtained clearly indicate that the chemomigratory activity of olfactorin is similar to that observed by exposing the cells to anosmin-1 in terms of the magnitude of the response and sensitivity to heparin, suggesting an interaction with heparan sulfate proteoglycans (HSPG) (Cariboni et al., 2004).
The adhesive properties of anosmin-1 seem to depend on the interaction with chains present on the cell surface or in the extracellular matrix and seem to be attributed to the 32 aa sequence present in the first FNIII repeat of the protein (SoussiYanicostas et al., 1998; Cariboni and Maggi, 2006). Furthermore, it has been shown that a single FNIII domain is sufficient for anosmin-1's action on GnRH neurons (González-Martínez et al., 2004; Hu et al., 2009). Olfactorin has a single FNIII repeat that could be responsible for such a similar effect. It has also been reported that after interaction with HSPGs and a preformed FGF2/FGFR1 complex, anosmin-1 is able to induce an amplification of the response mediated by the activation of FGFR1 through the formation of a multimeric complex (Hu et al., 2009) and the activation of the MAPK pathway (González-Martínez et al., 2004). Moreover, the activity of FGFR1 is modulated by heparan sulfate proteoglycans, justifying the responsivity to the heparin treatment described above (Sarrazin et al., 2011).

It is noteworthy that the region of anosmin-1 interacting with the FGFR1-FGF2-HSPG multimeric complex is in the N-terminal part of the protein, which includes the WAP domain and the first FNIII repeat, that is, the region showing the highest similarity in protein domains with the N-terminal region of olfactorin.

We then investigated if the effect of olfactorin could be mediated by the activation of the MAPK (MEK1/2) pathway. Although the effect of anosmin-1 on GN11 chemomigration has been assessed (Cariboni et al., 2004), the mechanism involved was so far not clarified. Here, we report that the pharmacological block of MEK1/2 with UO126 abolishes the stimulatory effect of anosmin-1 on GN11 cells. These results seem in apparent contrast with the reported involvement of PI3K in the FGFinduced migration of human GnRH neuroblasts and chicken GnRH neurons. (Hu et al., 2013). However, alternative activation of the intracellular pathway involved in the migration of mouseimmortalized GnRH neurons could be considered.

However, pretreating GN11 cells with UO126, we found a clear suppression of GN11 cell chemomigration induced by olfactorin, suggesting a link between the olfactorin effect and activation of such pathways.

Both MEK1/2-mediated pathways have been described as important downstream signals in modulating FGFR1-mediated mechanisms such as proliferation, differentiation, and cell migration (Boilly et al., 2000; Mason, 2007; Ornitz and Itoh, 2015). The hypothesis of the interaction of olfactorin with FGFR1 or other receptors that converge in the chemotactic response has been further investigated.

We also considered the possible interaction with vascular endothelial growth factor receptors (VEGFRs) or hepatocyte growth factors (HGFRs, Met) since these factors were found to 
modulate GnRH neuron migration (Giacobini et al., 2002; Maggi et al., 2005; Cariboni et al., 2007) and form complexes with HSPG (Sarrazin et al., 2011).

Using specific inhibitors for FGFRs, VEGFRs, and HGFRs, we were able to demonstrate that the effect of olfactorin seems to be mainly mediated by the FGFR1 receptor. In fact, while the inhibitor for FGFR1 was able to eliminate the chemotactic effect of olfactorin, the inhibitor of VEGFRs or HGFRs led to a quite strong general reduction of migration of both the control and olfactorin-treated cells. Still, the olfactorin-mediated stimulation of GN11 cell migration resulted in a significantly conserved response of the same order of magnitude observed in the absence of the blockers.

On the other hand, these results emphasize the important role of VEGF and HGF, possibly present in the control CM, on the migration of GN11 cells.

A definitive evaluation of functional interaction of olfactorin with FGF, VEGF, and HGF activities would require a pure preparation of the protein not currently available, rather than the olfactorin-enriched CM.

The observation that the FGFR inhibitor does not exert any inhibitory effect on the control CM but is instead able to eliminate the potentiating effect of olfactorin indicates that similarly to anosmin-1 (González-Martínez et al., 2004; Hu et al., 2009) FGFR could need the 'co-factors' anosmin-1 (olfactorin)/HSPG to be efficiently activated. Finally, a transcriptional analysis using an FGF-sensitive OSE luciferase reporter (Mccabe et al., 2015) confirms the functional interaction of olfactorin with FGFR signaling.

The region of anosmin- 1 that binds to FGFR1 is located in the $\mathrm{N}$-terminal portion of the protein, conserved in the olfactorin structure, and includes the first repetition FNIII, the region rich in cysteine (CR) and the WAP domain (Hu et al., 2009; MurciaBelmonte et al., 2010; Esteban et al., 2013; Murcia-Belmonte et al., 2014). By homology modeling, we found that anosmin-1 and olfactorin can interact with the FGFR1-FGF2 complex through a similar binding mode in which the WAP domain seems to play a central role.

The WAP domain of anosmin-1 properly contacts both the D2 region of FGFR1 and the FGF2 structure through a network of ionic contacts which involves the acidic residues of the domain of both anosmin-1 and olfactorin, while the FNIII.1 domain interacts with the apical part of the $\mathrm{D} 2$ region. Olfactorin may similarly interact with FGFR1/FGF2 complex with its WAP domain whereas FNIII.1 domain interaction involves a larger portion of the D2 region, compared to the corresponding contacts established by anosmin- 1 .

Overall, although the actual molecular interaction can be demonstrated by specific studies (Hu et al., 2009), the results of the experiments reported here converge to support the hypothesis of an anosmin-like effect of olfactorin on chemomigration of GN11 cells involving the FGF2/FGFR1 complex.

In vivo, the possible role of olfactorin for the development of olfactory nerves and GnRH neurons was investigated in zebrafish embryos, as previously done to study anosmin-1 (Whitlock et al., 2005). Two strains were used, the gnrh3:EGFP transgenic zebrafish strain, used to visualize the early anterior $\mathrm{GnRH}$ neurons (Abraham et al., 2008) and the omp $p^{2 k}: g a p-C F P^{r w 034}$ strain, used to visualize OMP + olfactory neurons (Garaffo et al., 2013). Upon downregulation of the $z$-umodl1 mRNA, transiently obtained using morpholino oligos, we observed that some GnRH3 axons took an altered trajectory and were abnormally fasciculated within the anterior commissure. Likewise, the projections of olfactory neurons labeled with the omp-CFP transgene showed a slightly altered trajectory and a reduced efficiency of glomeruli formation. These results suggest a role for umodl1 in the guidance and connectivity of olfactory axons and the organization of the GnRH arborization.

Interestingly, using similar reporter strains of zebrafish, very similar results were observed upon the depletion of the KS gene's orthologs $z$-kalla/b (Whitlock et al., 2005) and $z$-fgfrla (Garaffo et al., 2013) in olfactory neuron projections (Yanicostas et al., 2009), supporting the use of this animal model for studying the development of the olfactory/GnRH system and for the functional validation of putative KS-causing gene mutations (Messina et al., 2020).

Overall, these results provide the first evidence of a biological function of z-umodll in the development of the GnRH/olfactory system. Getting insights into Umodl1 requirements for the proper axonal elongation process of GnRH neurons from nose to brain, which is essential for the establishment of reproductive function, and the identification of the molecular signaling pathway used by z-umodl1 in GnRH neuron migration along with FGFR1 and downstream targets involved will be critical for future investigations.

The results reported in the present study indicate that olfactorin, similarly to anosmin-1, exerts control on the migration of GN11 neurons in vitro and on the development of GnRH projections and olfactory axons in vivo. On the other hand, the absence of an orthologous gene of ANOS1 in rodents leads to hypothesize olfactorin as a possible biological substitute of anosmin-1 during the development of olfactory and reproductive functions in these rodents. These considerations indirectly place UMODL1 among the candidate genes to be responsible for the forms of KS, still without a certain etiopathogenesis and open to new perspectives in the study of other diseases. In particular, UMODL1 is located on human chromosome 21 within the Down syndrome's critical region (autosomal recessive nonsyndromic deafness DFNB10 critical region) (Shibuya et al., 2004; Jiang et al., 2015). Future studies could unravel the biological bases of the olfactory and reproductive defects observed in a large fraction of patients with the Down's syndrome (Murphy and Jinich, 1996).

\section{DATA AVAILABILITY STATEMENT}

The raw data supporting the conclusions of this article will be made available by the authors without undue reservation.

\section{ETHICS STATEMENT}

The animal study was reviewed and approved by the Ethical Committee of the University of Torino and the Italian Ministry of Health (aut. N. 425/2016-PR, issued on 27 April 2016). 


\section{AUTHOR CONTRIBUTIONS}

EDS and RM designed the study and analyzed the data. LC, DB, and RM conducted experiments in vitro. GM, IC, and GZ conducted experiments on zebrafish. GV and SG performed computer modeling. RM, EDS, GM, and RM contributed to the writing and editing of the manuscript.

\section{FUNDING}

This work was supported by Università degli Studi di Milano (Research Support Plan, line 2, action B 2017-18) and a donation

\section{REFERENCES}

Abraham, E., Palevitch, O., Gothilf, Y., and Zohar, Y. (2010). Targeted Gonadotropin-Releasing Hormone-3 Neuron Ablation in Zebrafish: Effects on Neurogenesis, Neuronal Migration, and Reproduction. Endocrinology 151, 332-340. doi:10.1210/en.2009-0548

Abraham, E., Palevitch, O., Gothilf, Y., and Zohar, Y. (2009). The Zebrafish as a Model System for Forebrain GnRH Neuronal Development. Gen. Comp. Endocrinol. 164, 151-160. doi:10.1016/j.ygcen.2009.01.012

Abraham, E., Palevitch, O., Ijiri, S., Du, S. J., Gothilf, Y., and Zohar, Y. (2008). Early Development of Forebrain Gonadotrophin-Releasing Hormone (GnRH) Neurones and the Role of GnRH as an Autocrine Migration Factor. J. Neuroendocrinology 20, 394-405. doi:10.1111/j.1365-2826.2008.01654.x

Bassi, I., ANDRé, V., Marelli, F., Vezzoli, V., Merlo, G. R., Cariboni, A., et al. (2016). The Zebrafish: an Emerging Animal Model for Investigating the Hypothalamic Regulation of Reproduction. Minerva Endocrinol. 41, 250-265.

Boilly, B., Vercoutter-Edouart, A. S., Hondermarck, H., Nurcombe, V., and Le Bourhis, X. (2000). FGF Signals for Cell Proliferation and Migration through Different Pathways. Cytokine Growth Factor. Rev. 11, 295-302. S1359610100000149 [pii]. doi:10.1016/s1359-6101(00)00014-9

Bribián, A., Esteban, P. F., Clemente, D., Soussi-Yanicostas, N., Thomas, J.-L., Zalc, B., et al. (2008). A Novel Role for Anosmin-1 in the Adhesion and Migration of Oligodendrocyte Precursors. Devel Neurobio 68, 1503-1516. doi:10.1002/dneu. 20678

Bülow, H. E., Berry, K. L., Topper, L. H., Peles, E., and Hobert, O. (2002). Heparan Sulfate Proteoglycan-dependent Induction of Axon Branching and Axon Misrouting by the Kallmann Syndrome Gene Kal-1. Proc. Natl. Acad. Sci. 99, 6346-6351. doi:10.1073/pnas.092128099

Cariboni, A., Davidson, K., Rakic, S., Maggi, R., Parnavelas, J. G., and Ruhrberg, C. (2011). Defective Gonadotropin-Releasing Hormone Neuron Migration in Mice Lacking SEMA3A Signalling through NRP1 and NRP2: Implications for the Aetiology of Hypogonadotropic Hypogonadism. Hum. Mol. Genet. 20, 336-344. doi:10.1093/hmg/ddq468

Cariboni, A., Hickok, J., Rakic, S., Andrews, W., Maggi, R., Tischkau, S., et al. (2007). Neuropilins and Their Ligands Are Important in the Migration of Gonadotropin-Releasing Hormone Neurons. J. Neurosci. 27, 2387-2395. doi:10.1523/jneurosci.5075-06.2007

Cariboni, A., and Maggi, R. (2006). Kallmann's Syndrome, a Neuronal Migration Defect. Cell. Mol. Life Sci. 63, 2512-2526. doi:10.1007/s00018-005-5604-3

Cariboni, A., Pimpinelli, F., Colamarino, S., Zaninetti, R., Piccolella, M., Rumio, C., et al. (2004). The Product of X-Linked Kallmann's Syndrome Gene (KAL1) Affects the Migratory Activity of Gonadotropin-Releasing Hormone (GnRH)Producing Neurons. Hum. Mol. Genet. 13, 2781-2791. doi:10.1093/hmg/ ddh309

Cho, H.-J., Shan, Y., Whittington, N. C., and Wray, S. (2019). Nasal Placode Development, GnRH Neuronal Migration and Kallmann Syndrome. Front. Cel Dev. Biol. 7, 121. doi:10.3389/fcell.2019.00121

Chung, W. C. J., Matthews, T. A., Tata, B. K., and Tsai, P.-S. (2010). Compound Deficiencies in Multiple FGF Signaling Components Differentially Impact the of UILDM ONLUS (Section of Lecco, Italy) (R.M.); University di Torino (RiLo 2010 and 2020); and the Italian Telethon Foundation (GGP 20039) (GM).

\section{ACKNOWLEDGMENTS}

We thank the UILDM Lecco for the support. We additionally thank Giovanna Miccicchè for her technical assistance and Chiara Rigobello, Giulia Citterio, Gaia Corazzini, Matteo Paolillo, Greta Piazza, Gloria Zicari and Martina Pontiggia for the work carried out during the preparation of their original research thesis.

Murine GnRH System. J. Neuroendocrinol 22, no. JNE2024 [pii]. doi:10.1111/j. 1365-2826.2010.02024.X

Crippa, V., Sau, D., Rusmini, P., Boncoraglio, A., Onesto, E., Bolzoni, E., et al. (2010). The Small Heat Shock Protein B8 (HspB8) Promotes Autophagic Removal of Misfolded Proteins Involved in Amyotrophic Lateral Sclerosis (ALS). Hum. Mol. Genet. 19, 3440-3456. doi:10.1093/hmg/ddq257

De Castro, F., Seal, R., Maggi, R., and Nomenclature, G. O. H. C. F. K. (2017). ANOS1: a Unified Nomenclature for Kallmann Syndrome 1 Gene (KAL1) and Anosmin-1. Brief. Funct. Genomics 16, 205-210. doi:10.1093/bfgp/elw037

Di Schiavi, E., and Andrenacci, D. (2013). Invertebrate Models of Kallmann Syndrome: Molecular Pathogenesis and New Disease Genes. Curr. Genomics 14, 2-10. doi:10.2174/138920213804999174

Di Schiavi, E., Riano, E., Heye, B., Bazzicalupo, P., and Rugarli, E. I. (2005). UMODL1/Olfactorin Is an Extracellular Membrane-Bound Molecule with a Restricted Spatial Expression in Olfactory and Vomeronasal Neurons. Eur. J. Neurosci. 21, 3291-3300. doi:10.1111/j.1460-9568.2005.04164.x

Dodé, C., and Hardelin, J.-P. (2009). Kallmann Syndrome. Eur. J. Hum. Genet. 17, 139-146. doi:10.1038/ejhg.2008.206

Duan, C., and Allard, J. (2020). Gonadotropin-releasing Hormone Neuron Development in Vertebrates. Gen. Comp. Endocrinol. 292, 113465. doi:10. 1016/j.ygcen.2020.113465

Esteban, P. F., Murcia-Belmonte, V., García-González, D., and De Castro, F. (2013). The Cysteine-Rich Region and the Whey Acidic Protein Domain Are Essential for Anosmin-1 Biological Functions. J. Neurochem. 124, 708-720. doi:10.1111/jnc.12104

Favata, M. F., Horiuchi, K. Y., Manos, E. J., Daulerio, A. J., Stradley, D. A., Feeser, W. S., et al. (1998). Identification of a Novel Inhibitor of Mitogen-Activated Protein Kinase Kinase. J. Biol. Chem. 273, 18623-18632. doi:10.1074/jbc.273.29. 18623

Flynt, A. S., Li, N., Thatcher, E. J., Solnica-Krezel, L., and Patton, J. G. (2007). Zebrafish miR-214 Modulates Hedgehog Signaling to Specify Muscle Cell Fate. Nat. Genet. 39, 259-263. doi:10.1038/ng1953

Franco, B., Guioli, S., Pragliola, A., Incerti, B., Bardoni, B., Tonlorenzi, R., et al. (1991). A Gene Deleted in Kallmann's Syndrome Shares Homology with Neural Cell Adhesion and Axonal Path-Finding Molecules. Nature 353, 529-536. doi:10.1038/353529a0

Garaffo, G., Conte, D., Provero, P., Tomaiuolo, D., Luo, Z., Pinciroli, P., et al. (2015). The Dlx5 and Foxg1 Transcription Factors, Linked via miRNA-9 and -200, Are Required for the Development of the Olfactory and GnRH System. Mol. Cell Neurosci. 68, 103-119. doi:10.1016/j.mcn.2015.04.007

Garaffo, G., Provero, P., Molineris, I., Pinciroli, P., Peano, C., Battaglia, C., et al. (2013). Profiling, Bioinformatic, and Functional Data on the Developing Olfactory/GnRH System Reveal Cellular and Molecular Pathways Essential for This Process and Potentially Relevant for the Kallmann Syndrome. Front. Endocrinol. 4, 203. doi:10.3389/fendo.2013.00203

García-González, D., Murcia-Belmonte, V., Esteban, P. F., Ortega, F., Díaz, D., Sánchez-Vera, I., et al. (2016). Anosmin-1 Over-expression Increases Adult Neurogenesis in the Subventricular Zone and Neuroblast Migration to the Olfactory Bulb. Brain Struct. Funct. 221, 239-260. doi:10.1007/s00429-0140904-8 
Giacobini, P., Giampietro, C., Fioretto, M., Maggi, R., Cariboni, A., Perroteau, I., et al. (2002). Hepatocyte Growth Factor/scatter Factor Facilitates Migration of GN-11 Immortalized LHRH Neurons. Endocrinology 143, 3306-3315. doi:10. 1210/en.2002-220146

Giacobini, P., Messina, A., Wray, S., Giampietro, C., Crepaldi, T., Carmeliet, P., et al. (2007). Hepatocyte Growth Factor Acts as a Motogen and Guidance Signal for Gonadotropin Hormone-Releasing Hormone-1 Neuronal Migration. J. Neurosci. 27, 431-445. doi:10.1523/jneurosci.4979-06.2007

González-Martínez, D., Kim, S. H., Hu, Y., Guimond, S., Schofield, J., Winyard, P., et al. (2004). Anosmin-1 Modulates Fibroblast Growth Factor Receptor 1 Signaling in Human Gonadotropin-Releasing Hormone Olfactory Neuroblasts through a Heparan Sulfate-dependent Mechanism. J. Neurosci. 24, 10384-10392. doi:10.1523/jneurosci.3400-04.2004

Guagnano, V., Furet, P., Spanka, C., Bordas, V., Le Douget, M., Stamm, C., et al. (2011). Discovery of 3-(2,6-Dichloro-3,5-Dimethoxy-Phenyl)-1-\{6-[4-(4-EthylPiperazin-1-Yl)-Phenylamino]-Pyrimidin-4-Yl\}-1-Methyl-Urea (NVP-Bgj398), a Potent and Selective Inhibitor of the Fibroblast Growth Factor Receptor Family of Receptor Tyrosine Kinase. J. Med. Chem. 54, 7066-7083. doi:10.1021/jm2006222

Hardelin, J.-P., Julliard, A. K., Moniot, B., Soussi-Yanicostas, N., Verney, C., Schwanzel-Fukuda, M., et al. (1999). Anosmin-1 Is a Regionally Restricted Component of Basement Membranes and Interstitial Matrices during Organogenesis: Implications for the Developmental Anomalies of $\mathrm{X}$ Chromosome-Linked Kallmann Syndrome. Dev. Dyn. 215, 26-44. doi:10. 1002/(sici)1097-0177(199905)215:1<26:aid-dvdy4>3.0.co;2-d

Hardelin, J.-P. (2001). Kallmann Syndrome: towards Molecular Pathogenesis. Mol. Cell Endocrinol. 179, 75-81. doi:10.1016/s0303-7207(01)00462-2

Hu, Y., González-martínez, D., Kim, S.-H., and Bouloux, P. M. G. (2004). Crosstalk of Anosmin-1, the Protein Implicated in X-Linked Kallmann's Syndrome, with Heparan Sulphate and Urokinase-type Plasminogen Activator. Biochem. J. 384, 495-505. doi:10.1042/bj20041078

Hu, Y., Guimond, S. E., Travers, P., Cadman, S., Hohenester, E., Turnbull, J. E., et al. (2009). Novel Mechanisms of Fibroblast Growth Factor Receptor 1 Regulation by Extracellular Matrix Protein Anosmin-1. J. Biol. Chem. 284, 29905-29920. doi:10.1074/jbc.M109.049155

$\mathrm{Hu}$, Y., Poopalasundaram, S., Graham, A., and Bouloux, P.-M. (2013). GnRH Neuronal Migration and Olfactory Bulb Neurite Outgrowth Are Dependent on FGF Receptor 1 Signaling, Specifically via the PI3K P110a Isoform in Chick Embryo. Endocrinology 154, 388-399. doi:10.1210/en.2012-1555

Hu, Y., Sun, Z., Eaton, J. T., Bouloux, P. M. G., and Perkins, S. J. (2005). Extended and Flexible Domain Solution Structure of the Extracellular Matrix Protein Anosmin1 by X-ray Scattering, Analytical Ultracentrifugation and Constrained Modelling. J. Mol. Biol. 350, 553-570. doi:10.1016/j.jmb.2005.04.031

Hu, Y., Yu, H., Shaw, G., Pask, A. J., and Renfree, M. B. (2011). Kallmann Syndrome 1 Gene Is Expressed in the Marsupial Gonad1. Biol. Reprod. 84, 595-603. doi:10.1095/biolreprod.110.087437

Ishizaka, K., Suzuki, M., Kageyama, Y., Kihara, K., and Yoshida, K. (2002). Bone mineral Density in Hypogonadal Men Remains Low after Long-Term Testosterone Replacement. Asian J. Androl. 4, 117-121.

Jiang, X., Liu, C., Yu, T., Zhang, L., Meng, K., Xing, Z., et al. (2015). Genetic Dissection of the Down Syndrome Critical Region. Hum. Mol. Genet. 24, 6540-6551. doi:10.1093/hmg/ddv364

Katchalski-Katzir, E., Shariv, I., Eisenstein, M., Friesem, A. A., Aflalo, C., and Vakser, I. A. (1992). Molecular Surface Recognition: Determination of Geometric Fit between Proteins and Their Ligands by Correlation Techniques. Proc. Natl. Acad. Sci. 89, 2195-2199. doi:10.1073/pnas.89.6.2195

Kim, H.-J., Kim, J.-H., Bae, S.-C., Choi, J.-Y., Kim, H.-J., and Ryoo, H.-M. (2003). The Protein Kinase C Pathway Plays a central Role in the Fibroblast Growth Factor-Stimulated Expression and Transactivation Activity of Runx2. J. Biol. Chem. 278, 319-326. doi:10.1074/jbc.M203750200

Kloosterman, W. P., and Plasterk, R. H. A. (2006). The Diverse Functions of microRNAs in Animal Development and Disease. Develop. Cel 11, 441-450. doi:10.1016/j.devcel.2006.09.009

Kloosterman, W. P., Steiner, F. A., Berezikov, E., De Bruijn, E., Van De Belt, J., Verheul, M., et al. (2006). Cloning and Expression of New microRNAs from Zebrafish. Nucleic Acids Res. 34, 2558-2569. doi:10.1093/nar/gkl278

Limonta, P., Marelli, M. M., Moretti, R., Marzagalli, M., Fontana, F., and Maggi, R. (2018). GnRH in the Human Female Reproductive Axis. Vitam Horm. 107, 27-66. doi:10.1016/bs.vh.2018.01.003
Maccoll, G. S., Quinton, R., and Bülow, H. E. (2010). Biology of KAL1 and its Orthologs: Implications for X-Linked Kallmann Syndrome and the Search for Novel Candidate Genes. Front. Horm. Res. 39, 62-77. doi:10.1159/000312694

Maggi, R., Cariboni, A., Zaninetti, R., Samara, A., Stossi, F., Pimpinelli, F., et al. (2005). Factors Involved in the Migration of Neuroendocrine Hypothalamic Neurons. Arch. Ital. Biol. 143, 171-178.

Maggi, R., Cariboni, A. M., Marelli, M. M., Moretti, R. M., Andrè, V., Marzagalli, M., et al. (2016). GnRH and GnRH Receptors in the Pathophysiology of the Human Female Reproductive System. Hum. Reprod. Update 22, 358-381. doi:10.1093/humupd/dmv059

Maggi, R., Pimpinelli, F., Molteni, L., Milani, M., Martini, L., and Piva, F. (2000a). Immortalized Luteinizing Hormone-Releasing Hormone Neurons Show a Different Migratory Activity In Vitro. Endocrinology 141, 2105-2112. doi:10. 1210/endo.141.6.7494

Maggi, R., Pimpinelli, F., Rosati, B., Molteni, L., Motta, M., and Piva, F. (2000b). Immortalized Hypothalamic Neurons as a Model to Study the Physiopathology of the Migration of LHRH Neurons. Pflugers Archiv-European J. Physiol. 439, R277.

Maggi, R. (2020). "The Hypothalamus-Pituitary-Ovary Axis," in Female Reproductive Dysfunction. Editor B. F. F. Petraglia (Cham): Springer), 1-19.

Mason, I. (2007). Initiation to End point: the Multiple Roles of Fibroblast Growth Factors in Neural Development. Nat. Rev. Neurosci. 8, 583-596. doi:10.1038/ nrn2189

Mccabe, M. J., Hu, Y., Gregory, L. C., Gaston-Massuet, C., Alatzoglou, K. S., Saldanha, J. W., et al. (2015). Novel Application of Luciferase Assay for the In Vitro Functional Assessment of KAL1 Variants in Three Females with SeptoOptic Dysplasia (SOD). Mol. Cell Endocrinol. 417, 63-72. doi:10.1016/j.mce. 2015.09.010

Messina, A., Pulli, K., Santini, S., Acierno, J., Känsäkoski, J., Cassatella, D., et al. (2020). Neuron-Derived Neurotrophic Factor Is Mutated in Congenital Hypogonadotropic Hypogonadism. Am. J. Hum. Genet. 106, 58-70. doi:10. 1016/j.ajhg.2019.12.003

Miyasaka, N., Sato, Y., Yeo, S.-Y., Hutson, L. D., Chien, C.-B., Okamoto, H., et al. (2005). Robo2 Is Required for Establishment of a Precise Glomerular Map in the Zebrafish Olfactory System. Development 132, 1283-1293. doi:10.1242/dev. 01698

Murcia-Belmonte, V., Esteban, P. F., García-González, D., and De Castro, F. (2010). Biochemical Dissection of Anosmin-1 Interaction with FGFR1 and Components of the Extracellular Matrix. J. Neurochem. 115, 1256-1265. doi:10. 1111/j.1471-4159.2010.07024.x

Murcia-Belmonte, V., Esteban, P. F., Martínez-Hernández, J., Gruart, A., Luján, R., Delgado-García, J. M., et al. (2016). Anosmin-1 Over-expression Regulates Oligodendrocyte Precursor Cell Proliferation, Migration and Myelin Sheath Thickness. Brain Struct. Funct. 221, 1365-1385. doi:10.1007/s00429-0140977-4

Murcia-Belmonte, V., Medina-Rodríguez, E. M., Bribián, A., De Castro, F., and Esteban, P. F. (2014). ERK1/2 Signaling Is Essential for the Chemoattraction Exerted by Human FGF2 and Human Anosmin-1 on Newborn Rat and Mouse OPCs via FGFR1. Glia 62, 374-386. doi:10.1002/glia.22609

Murphy, C., and Jinich, S. (1996). Olfactory Dysfunction in Down's Syndrome. Neurobiol. Aging 17, 631-637. doi:10.1016/0197-4580(96)00008-5

Nishizaki, R., Ota, M., Inoko, H., Meguro, A., Shiota, T., Okada, E., et al. (2009). New Susceptibility Locus for High Myopia Is Linked to the Uromodulin-like 1 (UMODL1) Gene Region on Chromosome 21q22.3. Eye 23, 222-229. doi:10. 1038/eye.2008.152

Ornitz, D. M., and Itoh, N. (2015). The Fibroblast Growth Factor Signaling Pathway. Wires Dev. Biol. 4, 215-266. doi:10.1002/wdev.176

Papadopoulos, J. S., and Agarwala, R. (2007). COBALT: Constraint-Based Alignment Tool for Multiple Protein Sequences. Bioinformatics 23, 1073-1079. doi:10.1093/bioinformatics/btm076

Park, O.-J., Kim, H.-J., Woo, K.-M., Baek, J.-H., and Ryoo, H.-M. (2010). FGF2activated ERK Mitogen-Activated Protein Kinase Enhances Runx2 Acetylation and Stabilization. J. Biol. Chem. 285, 3568-3574. doi:10.1074/ jbc.M109.055053

Pedretti, A., Mazzolari, A., Gervasoni, S., Fumagalli, L., and Vistoli, G. (2021). The VEGA Suite of Programs: an Versatile Platform for Cheminformatics and Drug Design Projects. Bioinformatics 37, 1174-1175. doi:10.1093/bioinformatics/ btaa774 
Peters, L. M., Belyantseva, I. A., Lagziel, A., Battey, J. F., Friedman, T. B., and Morell, R. J. (2007). Signatures from Tissue-specific MPSS Libraries Identify Transcripts Preferentially Expressed in the Mouse Inner Ear. Genomics 89, 197-206. doi:10.1016/j.ygeno.2006.09.006

Phillips, J. C., Braun, R., Wang, W., Gumbart, J., Tajkhorshid, E., Villa, E., et al. (2005). Scalable Molecular Dynamics with NAMD. J. Comput. Chem. 26, 1781-1802. doi:10.1002/jcc.20289

Polverino, A., Coxon, A., Starnes, C., Diaz, Z., Demelfi, T., Wang, L., et al. (2006). AMG 706, an Oral, Multikinase Inhibitor that Selectively Targets Vascular Endothelial Growth Factor, Platelet-Derived Growth Factor, and Kit Receptors, Potently Inhibits Angiogenesis and Induces Regression in Tumor Xenografts. Cancer Res. 66, 8715-8721. doi:10.1158/0008-5472.can-05-4665

Reed, R. R. (2004). After the Holy Grail. Cell 116, 329-336. doi:10.1016/s00928674(04)00047-9

Rugarli, E. I., Di Schiavi, E., Hilliard, M. A., Arbucci, S., Ghezzi, C., Facciolli, A., et al. (2002). The Kallmann Syndrome Gene Homolog in C. elegans Is Involved in Epidermal Morphogenesis and Neurite Branching. Development 129, 1283-1294. doi:10.1242/dev.129.5.1283

Šali, A., and Blundell, T. L. (1993). Comparative Protein Modelling by Satisfaction of Spatial Restraints. J. Mol. Biol. 234, 779-815. doi:10.1006/jmbi.1993.1626

Sammeta, N., Hardin, D. L., and Mcclintock, T. S. (2010). Uncx Regulates Proliferation of Neural Progenitor Cells and Neuronal Survival in the Olfactory Epithelium. Mol. Cell Neurosci. 45, 398-407. doi:10.1016/j.mcn. 2010.07.013

Sarrazin, S., Lamanna, W. C., and Esko, J. D. (2011). Heparan Sulfate Proteoglycans. Cold Spring Harbor Perspect. Biol. 3, a004952. doi:10.1101/ cshperspect.a004952

Sato, Y., Miyasaka, N., and Yoshihara, Y. (2005). Mutually Exclusive Glomerular Innervation by Two Distinct Types of Olfactory Sensory Neurons Revealed in Transgenic Zebrafish. J. Neurosci. 25, 4889-4897. doi:10.1523/jneurosci.067905.2005

Sattler, M., Pride, Y. B., Ma, P., Gramlich, J. L., Chu, S. C., Quinnan, L. A., et al. (2003). A Novel Small Molecule Met Inhibitor Induces Apoptosis in Cells Transformed by the Oncogenic TPR-MET Tyrosine Kinase. Cancer Res. 63, 5462-5469.

Schlessinger, J., Plotnikov, A. N., Ibrahimi, O. A., Eliseenkova, A. V., Yeh, B. K., Yayon, A., et al. (2000). Crystal Structure of a Ternary FGF-FGFR-Heparin Complex Reveals a Dual Role for Heparin in FGFR Binding and Dimerization. Mol. Cel 6, 743-750. doi:10.1016/s1097-2765(00)00073-3

Schwanzel-Fukuda, M., Bick, D., and Pfaff, D. W. (1989). Luteinizing HormoneReleasing Hormone (LHRH)-expressing Cells Do Not Migrate Normally in an Inherited Hypogonadal (Kallmann) Syndrome. Mol. Brain Res. 6, 311-326. doi:10.1016/0169-328x(89)90076-4

Shibuya, K., Nagamine, K., Okui, M., Ohsawa, Y., Asakawa, S., Minoshima, S., et al. (2004). Initial Characterization of an Uromodulin-like 1 Gene on Human Chromosome 21q22.3. Biochem. Biophysical Res. Commun. 319, 1181-1189. doi:10.1016/j.bbrc.2004.05.094

Soussi-Yanicostas, N., Faivre-Sarrailh, C., Hardelin, J. P., Levilliers, J., Rougon, G., and Petit, C. (1998). Anosmin-1 Underlying the X Chromosome-Linked Kallmann Syndrome Is an Adhesion Molecule that Can Modulate Neurite Growth in a Cell-type Specific Manner. J. Cel Sci 111 (Pt 19), 2953-2965. doi:10. 1242 /jcs.111.19.2953

Soussi-Yanicostas, N., Hardelin, J. P., Arroyo-Jimenez, M. M., Ardouin, O., Legouis, R., Levilliers, J., et al. (1996). Initial Characterization of Anosmin-1, a Putative Extracellular Matrix Protein Synthesized by Definite Neuronal Cell Populations in the central Nervous System. J. Cel Sci 109 (Pt 7), 1749-1757. doi:10.1242/jcs.109.7.1749

Soussi-Yanicostas, N., De Castro, F., Julliard, A. K., Perfettini, I., Chédotal, A., and Petit, C. (2002). Anosmin-1, Defective in the X-Linked Form of Kallmann Syndrome, Promotes Axonal branch Formation from Olfactory Bulb Output Neurons. Cell 109, 217-228. doi:10.1016/s0092-8674(02)00713-4
Stamou, M. I., and Georgopoulos, N. A. (2018). Kallmann Syndrome: Phenotype and Genotype of Hypogonadotropic Hypogonadism. Metabolism 86, 124-134. doi:10.1016/j.metabol.2017.10.012

Swee, D. S., Quinton, R., and Maggi, R. (2021). Recent Advances in Understanding and Managing Kallmann Syndrome. Fac. Rev. 10, 37. doi:10.12703/r/10-37

Tobet, S. A., Sower, S. A., and Schwarting, G. A. (1997). Gonadotropin-releasing Hormone Containing Neurons and Olfactory Fibers during Development: from Lamprey to Mammals. Brain Res. Bull. 44, 479-486. doi:10.1016/s03619230(97)00229-3

Tovchigrechko, A., and Vakser, I. A. (2006). GRAMM-X Public Web Server for Protein-Protein Docking. Nucleic Acids Res. 34, W310-W314. doi:10.1093/nar/ gkl206

Wang, L., Vervoort, V., Wallez, Y., Coré, N., Cremer, H., and Pasquale, E. B. (2010). The SRC Homology 2 Domain Protein Shep1 Plays an Important Role in the Penetration of Olfactory Sensory Axons into the Forebrain. J. Neurosci. 30 , 13201-13210. doi:10.1523/jneurosci.3289-10.2010

Wang, W., Tang, Y., Ni, L., Kim, E., Jongwutiwes, T., Hourvitz, A., et al. (2012). Overexpression of Uromodulin-Like1 Accelerates Follicle Depletion and Subsequent Ovarian Degeneration. Cell Death Dis 3, e433. doi:10.1038/cddis. 2012.169

Webb, B., and Sali, A. (2016). Comparative Protein Structure Modeling Using MODELLER. Curr. Protoc. Bioinformatics 5.6.1, 5.6.37-13210. doi:10.1002/ cpbi.3

Whitlock, K. E., Smith, K. M., Kim, H., and Harden, M. V. (2005). A Role For foxd3 and sox10 in the Differentiation of Gonadotropin-Releasing Hormone (GnRH) Cells in the zebrafish Danio rerio. Development 132, 5491-5502. doi:10.1242/ dev.02158

Yanicostas, C., Herbomel, E., Dipietromaria, A., and Soussi-Yanicostas, N. (2009). Anosmin-1a Is Required for Fasciculation and Terminal Targeting of Olfactory Sensory Neuron Axons in the Zebrafish Olfactory System. Mol. Cell Endocrinol. 312, 53-60. doi:10.1016/j.mce.2009.04.017

Yoshida, T., Ito, A., Matsuda, N., and Mishina, M. (2002). Regulation by Protein Kinase A Switching of Axonal Pathfinding of Zebrafish Olfactory Sensory Neurons through the Olfactory Placode-Olfactory Bulb Boundary. J. Neurosci. 22, 4964-4972. doi:10.1523/jneurosci.2212-04964.2002

Zhao, Y., Lin, M.-C. A., Farajzadeh, M., and Wayne, N. L. (2013). Early Development of the Gonadotropin-Releasing Hormone Neuronal Network in Transgenic Zebrafish. Front. Endocrinol. 4, 107. doi:10.3389/fendo.2013.00107

Zuccarini, G., D'Atri, I., Cottone, E., Mackie, K., Shainer, I., Gothilf, Y., et al. (2019). Interference with the Cannabinoid Receptor CB1R Results in Miswiring of GnRH3 and AgRP1 Axons in Zebrafish Embryos. Ijms 21, 168. doi:10.3390/ ijms 21010168

Conflict of Interest: The authors declare that the research was conducted in the absence of any commercial or financial relationships that could be construed as a potential conflict of interest.

Publisher's Note: All claims expressed in this article are solely those of the authors and do not necessarily represent those of their affiliated organizations, or those of the publisher, the editors, and the reviewers. Any product that may be evaluated in this article, or claim that may be made by its manufacturer, is not guaranteed or endorsed by the publisher.

Copyright ( 2022 Di Schiavi, Vistoli, Moretti, Corrado, Zuccarini, Gervasoni, Casati, Bottai, Merlo and Maggi. This is an open-access article distributed under the terms of the Creative Commons Attribution License (CC BY). The use, distribution or reproduction in other forums is permitted, provided the original author(s) and the copyright owner(s) are credited and that the original publication in this journal is cited, in accordance with accepted academic practice. No use, distribution or reproduction is permitted which does not comply with these terms. 